\title{
Coseismic and early postseismic slips associated with the 2011 off the Pacific coast of Tohoku Earthquake sequence: EOF analysis of GPS kinematic time series
}

\author{
Hiroshi Munekane \\ Geospatial Information Authority of Japan, 1 Kitasato, Tsukuba, Ibaraki 305-0811, Japan \\ (Received December 22, 2011; Revised June 1, 2012; Accepted July 25, 2012; Online published January 28, 2013)
}

\begin{abstract}
GPS kinematic time series are analyzed to estimate slip distributions for the $M_{\mathrm{w}} 9.02011$ off the Pacific coast of Tohoku Earthquake sequence. Empirical orthogonal function (EOF) analysis is employed to enhance the signal-to-noise ratio of the original time series. The coseismic, and subsequent postseismic, deformations of the foreshock can be described by a single mode, suggesting that the extent of the source for both events must be similar. The total moment magnitude of the afterslip following the foreshock is estimated to be $M_{\mathrm{w}} 7.1$ with a decay time of 0.63 days. The magnitude of the afterslip was larger for its duration than was anticipated by the scaling law for a typical slow earthquake, although two previous earthquakes in adjacent regions showed the same tendency as that in the present case. The pattern of slip of the mainshock and the subsequent afterslips and aftershocks indicates that each slip occurs in a region adjacent to that of the previous slips in a complementary manner. Finally, in the course of the EOF analysis, the modes representing the thermal expansion of the GPS pillars are clearly identified.
\end{abstract}

Key words: Kinematic GPS, EOF, coseismic slip, afterslip.

\section{Introduction}

The $M_{\mathrm{w}} 9.02011$ off the Pacific coast of Tohoku Earthquake (hereafter referred to as the 2011 Tohoku-oki earthquake) occurred on March 11, 2011, and ruptured the plate interface between the subducting Pacific plate and the overriding Okhotsk plate. One of the characteristics of this mega earthquake is that it was accompanied by a large foreshock and a sequence of adjacent aftershocks (Fig. 1). The $M_{\mathrm{w}} 7.3$ foreshock occurred on March 9 at 2:45 UT, and significant afterslip followed (Miyazaki et al., 2011). The $M_{\mathrm{w}} 9.0$ mainshock occurred on March 11 at 5:46 UT. Thereafter, three significant aftershocks with magnitudes of $M_{\mathrm{w}} 7.4,7.7$, and 7.5 followed at 6:08, 6:15, and 6:25 UT respectively (Nishimura et al., 2011); these aftershocks were followed by afterslip (Ito et al., 2011). Hereafter, the above three aftershocks are referred to as the Sanriku-oki $\left(M_{\mathrm{w}} 7.4\right)$, Ibaraki-oki $\left(M_{\mathrm{w}} 7.7\right)$ and outer-rise $\left(M_{\mathrm{w}} 7.5\right)$ aftershocks. All of the earthquakes mentioned above were thrust-type earthquakes at the plate boundary; except the outer-rise aftershock, which was a normal-type earthquake occurring at the outer swell of the Japan trench.

It is important to resolve the deformations associated with earthquakes and afterslips and to estimate slip for individual events separately to obtain insights into slip propagation and stress transfer. For this purpose, GPS kinematic time series are useful. Miyazaki and Larson (2008) success-

Copyright (C) The Society of Geomagnetism and Earth, Planetary and Space Sciences (SGEPSS); The Seismological Society of Japan; The Volcanological Society of Japan; The Geodetic Society of Japan; The Japanese Society for Planetary Sciences; TERRAPUB.

doi:10.5047/eps.2012.07.009 fully used the GPS kinematic time series from the Japanese nationwide GPS network (GEONET) to study the 2003 Tokachi-oki earthquake sequence: One of their results was that the afterslip between the mainshock and the $M 7.4$ aftershock occurred in a region to the southwest of the mainshock, which possibly triggered the aftershock in the southwest. However, identifying the deformation caused by each earthquake and afterslip in the case of the 2011 Tohoku-oki earthquake sequence is a challenging task since the aftershocks and afterslips occurred in a very short time interval after the mainshock. It is, therefore, necessary to enhance the signal-to-noise ratio of the GPS kinematic time series to extract the deformation field corresponding to each earthquake and to afterslip at the GPS observation sites; these data are needed to estimate the associated slip on the plate interface.

Nishimura et al. (2011) constructed fault models for the 2011 Tohoku-oki earthquake sequence using the GPS kinematic time series of the GEONET stations. They successfully estimated the fault models of the foreshock, mainshock, and the Sanriku-oki and Ibaraki-oki aftershocks. However, they did not determine fault models for the outerrise aftershock or for afterslip associated with the foreshock and mainshock, because the original GPS kinematic time series did not have a sufficient signal-to-noise ratio for deriving reliable deformation fields to permit them to infer slip on the faults.

Empirical orthogonal function (EOF) analysis is one method used to enhance the signal-to-noise ratio of any time series. EOF analysis, also known as principal component analysis, is used to decompose a simultaneously observed 


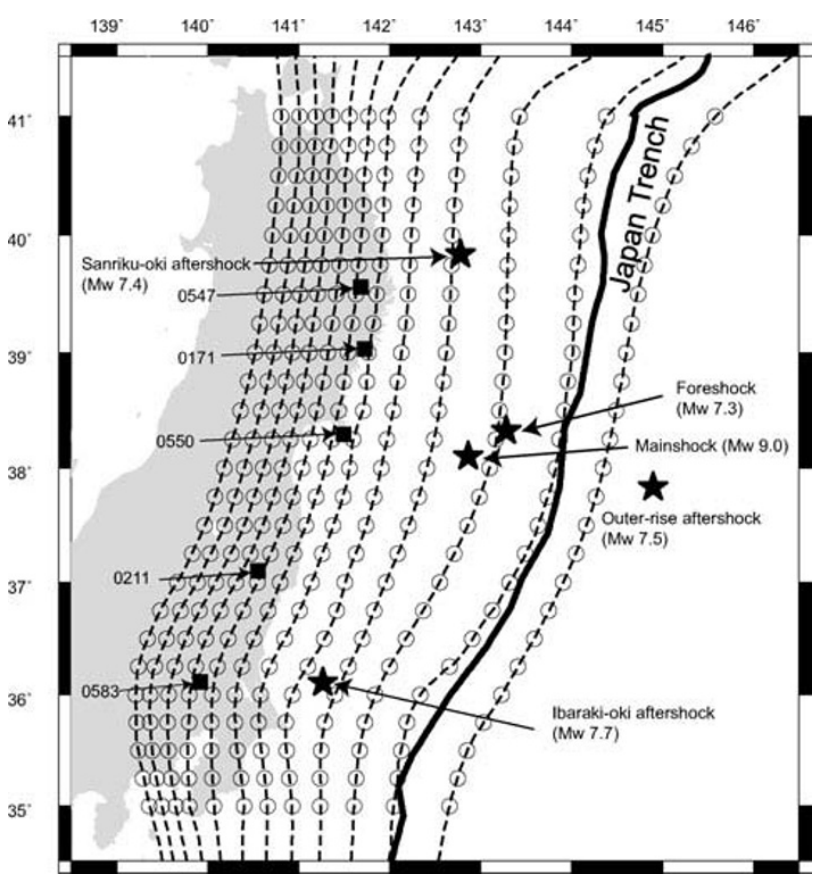

Fig. 1. Map showing the distribution of the epicenters of the 2011 Tohoku-oki earthquake sequence and nodes used in slip inversion. Stars denote the locations of the epicenters of the foreshock, mainshock, and aftershocks. Open circles denote nodes used in slip inversion. Broken lines denote the depth contour of the subducting plate interface with an interval of $10 \mathrm{~km}$. Solid squares denote the locations of sites whose time series are shown in Figs. 5, 14 and 22.

time series into a superposition of modes that are composed of the principal components and corresponding eigenvectors. The principal components represent temporal variations, and the eigenvectors represent the spatial responses corresponding to the principal components. Although this decomposition is mathematical and has no physical meaning, it may be possible to judge whether each mode represents noise or signal from the appearance of the principal components or eigenvectors. In this case, it may be possible to construct a denoised time series with a higher signal-to-noise ratio by adding up modes that are considered to be signals, or by removing modes that are considered to be noise, from the original time series. For example, Aoki and Scholz (2003) applied EOF analysis to tide gauge data and GPS-derived vertical coordinate time series and constructed a denoised time series by using only the first mode. They subsequently used it to extract the interseismic vertical deformation field of the Japanese islands. Dong et al. (2006) used EOF analysis to identify/remove the modes corresponding to common mode errors (CMEs) that are often associated with the GPS time series. In the case of the 2011 Tohoku-oki earthquake, Chang and Chao (2011) applied EOF analysis to the GPS kinematic time series obtained from GEONET and identified several modes corresponding to the coseismic, and postseismic, deformations.

The purpose of this study is to expand the study of Nishimura et al. (2011) to estimate slip distributions associated with the earthquakes and afterslip from the GPS kinematic time series to obtain insights into slip evolution and stress transfer. For this purpose, the study of Chang and Chao (2011) has been extended to extract a reliable deformation field associated with the earthquakes and afterslip from the EOF modes corresponding to the coseismic, and postseismic, deformations.

\section{Methods}

\subsection{GPS analysis}

I analyzed 30-s GPS data obtained from GEONET stations using GIPSY software in the Precise Point Positioning (PPP) mode (Zumberge et al., 1997) from day of year (DOY) 065 (March 6) to DOY 070 (March 11) of 2011 using the IGS08 reprocessed GPS orbit/clock products published by the Jet Propulsion Laboratory (JPL) (Desai et al., 2011). In the GPS analysis, the positions are estimated every $30 \mathrm{~s}$ along with carrier-phase ambiguities (Bertiger et $a l ., 2010)$ and Zenith Wet Delays (ZWDs), atmospheric gradient parameters in the N/S and E/W directions, and site clocks by means of a Kalman filtering. ZWDs and atmospheric gradient parameters are modeled as random walk processes with a processing noise of 3.0 and $0.3 \mathrm{~mm} / \sqrt{\mathrm{hr}}$, respectively, and site positions are modeled as white noise. I used data from satellites with an elevation angle of $10^{\circ}$ or larger, and used the VMF1 mapping function (Boehm et al., 2006) to relate slant tropospheric delays to those at zenithal directions. The ocean tidal loading was corrected with the GOTIC2 software (Matsumoto et al., 2001) and the NAO99Jb model (Matsumoto et al., 2000) in the center of mass of the solid earth (CE) frame. To mitigate the effect of multipath on the estimated position time series, I first calculated the $1^{\circ} \times 1^{\circ}$ postfit phase residual maps by stacking postfit residuals of the static GPS solutions from DOY 058 to DOY 064 and used the residual maps to correct for the effect of multipath at the observation level (Iwabuchi et al., 2004).

The GPS time series thus calculated contain significant CMEs, which are considered to be caused by unmodeled, or mismodeled, motions of satellite orbits, reference frame, or earth orientation parameters (Dong et al., 2006). The CMEs were removed prior to the EOF analysis to avoid any leakage of coseismic/postseismic signals into the modes representing CMEs. For this purpose, I first stacked the position time series of chosen sites on an epoch-by-epoch basis to obtain the CME time series. Note that the sites chosen for the CME evaluation were chosen to minimize real deformation during each time period. I subsequently subtracted the estimated CMEs from the position time series to obtain the filtered position time series (Wdowinski et al., 1997).

When stacking the position time series to obtain the CME time series, the thermal expansion of the pillars of the GPS stations due to sunlight needs to be considered. The pillars of GEONET stations consist of four types depending on the time of installation (hereafter referred to "93", "94", "95", and "02" types). 93-, 94-, and 95-type pillars consist of single stainless steel tubes and are known to move in a direction away from the sun, as the faces of pillars heated by sunlight expand so that the pillar bends away from the sun (Hatanaka et al., 2005). On the other hand, the 02-type pillars consist of coaxial dual tubes and are not susceptible 
to thermal expansion by sunlight. Therefore, I stacked the position time series of the GPS stations that are equipped with 02-type pillars only, to avoid contamination of the CMEs by the thermal expansion of pillars. The details of the stacking for each specific case will be described in the next section.

\subsection{EOF analysis}

I then constructed the data matrix $\mathbf{X}$, whose columns contain the demeaned components (north and east) of position time series spanning $m$ epochs from $n$ stations in the network. The covariance matrix of $X$ is decomposed as:

$$
B=V \Lambda V^{T}
$$

where covariance matrix $B$ is defined as

$$
B=\frac{1}{m-1} X^{T} X
$$

and $\Lambda$ is a diagonal matrix containing eigenvalues $\left\{\lambda_{k}\right\}$ (Dong et al., 2006).

The $(m \times n)$ matrix $\mathbf{X}$ is subsequently decomposed into the following form:

$$
X=A V^{T}
$$

or

$$
X_{i j}=\sum_{k=1}^{K} a_{i k} v_{j k},
$$

where the $k$ th column of $A=\left\{a_{i j}\right\}$ represents the principal component of mode $k$ and the $k$ th column of $V=\left\{v_{i j}\right\}$ represents its corresponding eigenvectors (Dong et al., 2006). In Eq. (4), the modes are arranged in descending order, and eigenvectors for each mode are normalized by their maximum values. $K$ represents the maximum number of modes.

Note that total variance of the time series equals $\operatorname{tr} \Lambda$, and the contribution of the $k$ th mode to the total variance $r_{k}$ is shown to be

$$
r_{k}=\frac{\lambda_{k}}{\operatorname{tr} \Lambda}
$$

where $\lambda_{k}$ corresponds to the $k$ th eigenvalue.

The EOF analysis is performed using the program "pca" from the QOCA package (Dong et al., 2006). The east and north components were simultaneously analyzed so that both components share the same principal components so as to make the modes corresponding to earthquakes and afterslip easier to identify, whilst in Chang and Chao (2011) analyzed each component separately. I did not include the vertical components in the EOF analysis since the large noises in the vertical components affect the estimated principal components (and eigenvectors) significantly. Instead, I calculated eigenvectors for the vertical components using the least-squares method, while assuming that the vertical components share the same principal components as the horizontal ones.

After performing the EOF analysis, I selected the modes that may represent coseismic/postseismic signals on the basis of the appearance of the principal components and eigenvectors. Thereafter, the filtered time series were constructed using the following equation:

$$
\tilde{X}_{i j}=\sum_{k: \text { selected modes }} a_{i k} v_{j k},
$$

which resembles Eq. (4), but the summation is only done for the modes that are considered to represent coseismic/postseismic signals. Details of the EOF analysis for each specific case will be described in the next section.

\subsection{Slip inversion}

I then calculated coseismic/postseismic deformations at the GPS stations as the difference between the median positions of two specified time windows, using the filtered time series, and used them to invert for the slips at the plate boundaries. I used both the horizontal and vertical components of the deformation field in the inversion. Since vertical components are noisier than horizontal components, the noise sigma of the vertical components was tentatively assigned a value three times that of the horizontal components. The program "tdefnode" (McCaffrey, 2009) was used for the slip inversion. The slip distribution is represented as three-parameter downdip Gaussian functions of depth at 25 profiles along the Japan trench between $35^{\circ} \mathrm{N}$ and $41^{\circ} \mathrm{N}$, and between 0 and $110 \mathrm{~km}$ in depth (Fig. 1). The Gaussian functions represent mean depth, amplitude, and spread of slip at each segment. In the inversion, these functions at each segment and slip azimuth representing whole segments are estimated by a combination of grid search and simulated annealing with Green's functions calculated using an elastic halfspace dislocation model (Okada, 1992) with a rigidity of $40 \mathrm{GPa}$. I used a plate boundary geometry estimated by Nakajima and Hasegawa (2006) to model the faults between the plates. Finally, the seismic moment was calculated for each earthquake/afterslip from the estimated slip distribution, assuming the same rigidity.

\section{Results}

\subsection{Foreshock and its afterslip}

I analyzed the position time series of the 289 GEONET stations located in the area of $138-143^{\circ} \mathrm{E}$ by $36-41^{\circ} \mathrm{N}$ from 13:30 on March 6 to 05:45 on March 11 (hereafter referred to as period A). Prior to the EOF analysis, I corrected for the CME time series by subtracting the CME time series obtained by stacking 38 position time series of the GEONET stations that are equipped with 02-type pillars and are outside the region $140-143^{\circ} \mathrm{E}$ by $37-40^{\circ} \mathrm{N}$ where notable coseismic/postseismic deformations associated with the foreshock are observed.

The results from the EOF analysis during period A are shown in Figs. 2-4. Figure 2 shows the eigenvectors for each mode. It is apparent from Fig. 2 that mode 1 represents the coseismic, or postseismic, deformations caused by slip on an offshore fault. Modes 2 and 3 represent the coherent northward/southward and eastward/westward shift of the majority of the stations in the network. Figure 3 shows the principal components for each mode. In mode 1 , one can distinguish the coseismic jump, and subsequent postseismic relaxation, that may be fit by an exponential decay function (Shen et al., 1994). On the other hand, the rest of the modes show no characteristics of coseismic jump or subsequent postseismic relaxation. Figure 4 shows the contribution of each mode to the total variance. Mode 1 contributes approximately $15 \%$ of the total variance. The contributions of the other modes are minor; it is less than $1.1 \%$ for mode 4 and other higher modes. Therefore, it is con- 
Mode 1

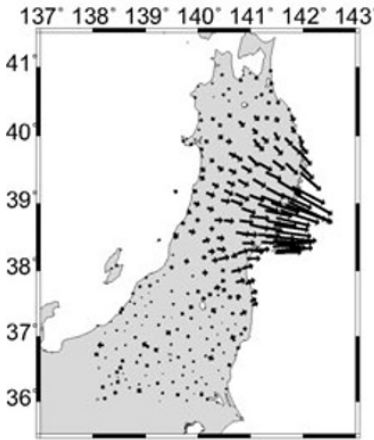

Mode 5

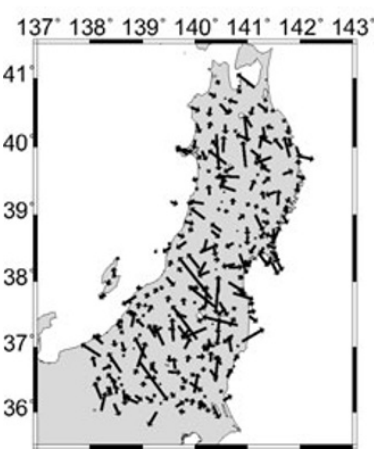

Mode 2

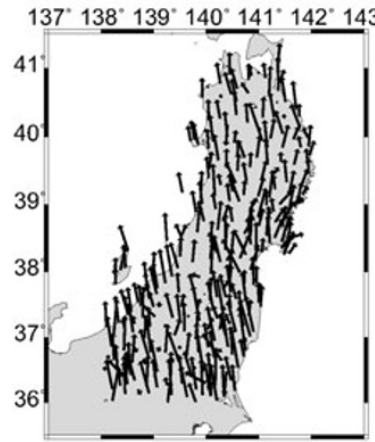

Mode 6

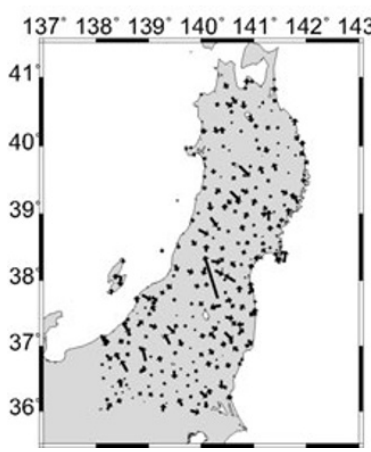

Mode 3

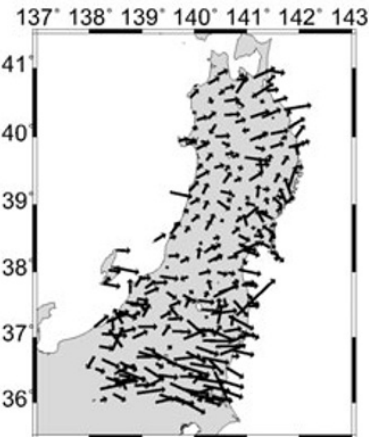

Mode 7

$137^{*} 138^{\circ} 139^{*} 140^{*} 141^{*} 142^{*} 143^{*}$

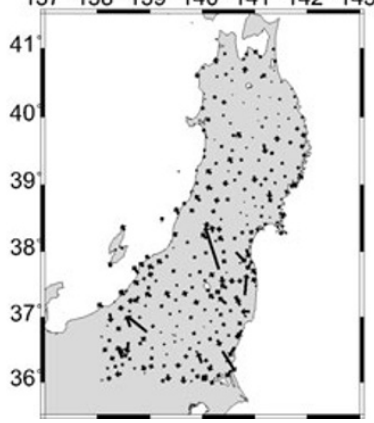

Mode 4

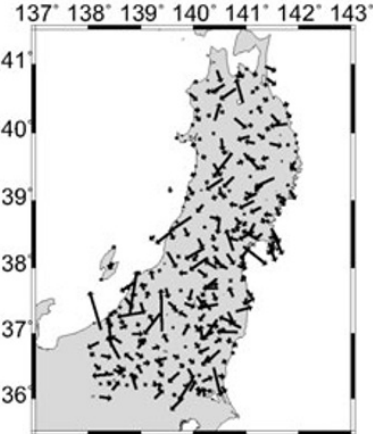

Mode 8

$137^{\circ} 138^{\circ} 139^{\circ} 140^{\circ} 141^{\circ} 142^{\circ} 143^{\circ}$

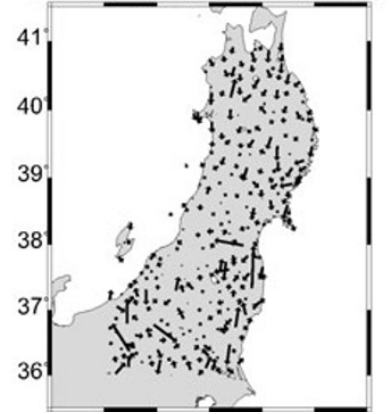

Fig. 2. The distribution of the eigenvectors for the first 8 modes during period A. Note that the eigenvectors for each mode are normalized by their maximum values.

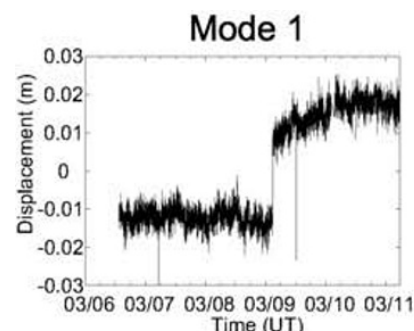

Mode 5

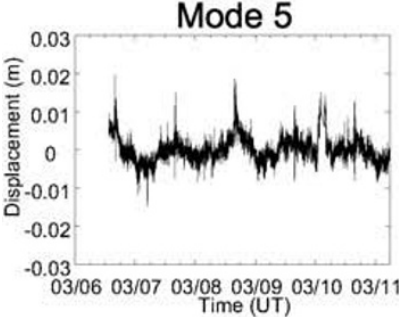

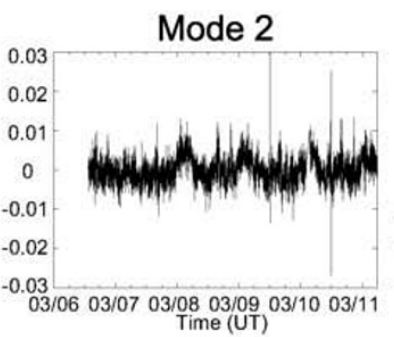

Mode 6

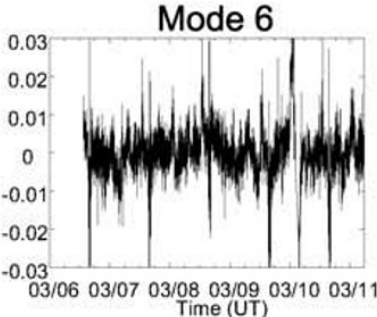

Mode 3

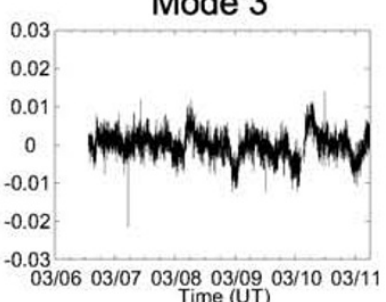

Mode 7

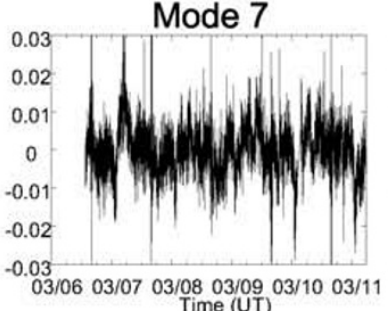

Mode 4

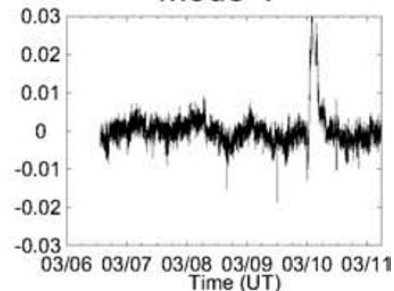

Mode 8

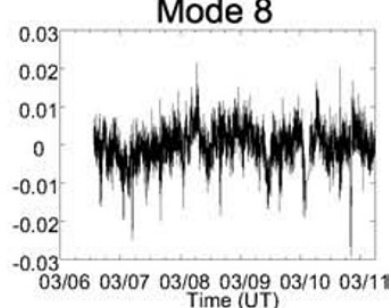

Fig. 3. The principal components for the first 8 modes during period A.

cluded that only mode 1 is relevant to the coseismic deformations and subsequent postseismic deformations. Thereafter, I constructed the filtered position time series at the GEONET stations using Eq. (6) with mode 1 only. Figure 5 shows the position time series at two typical GEONET stations. One can see that the coseismic jump and the subsequent postseismic deformations are well reproduced in the filtered time series.

The coseismic deformation associated with the foreshock was then calculated by considering the difference between the median positions at 2:40-2:45 and 2:50-2:55 on March

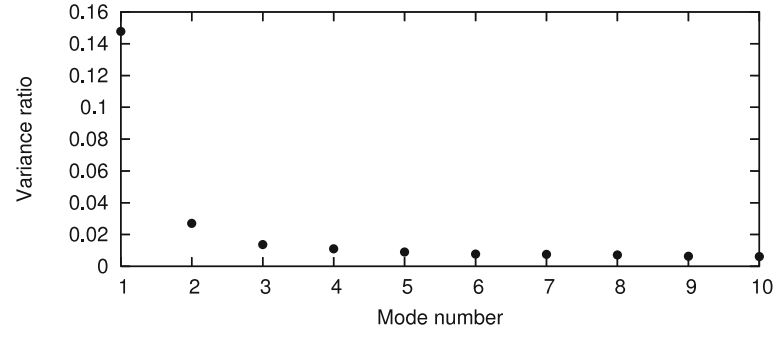

Fig. 4. The ratio of the variance of each mode to the total variance during period A. 

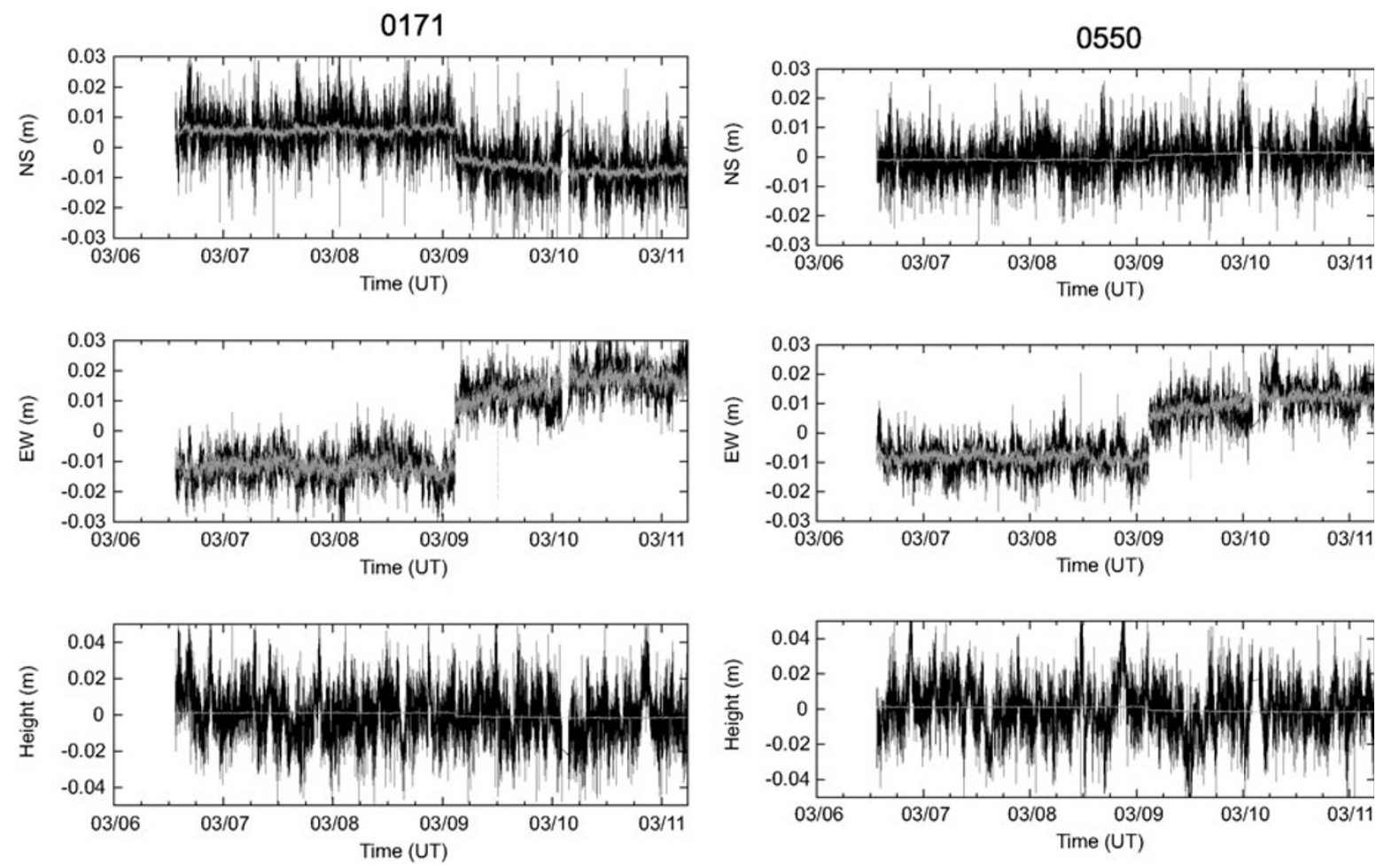

Fig. 5. The position time series at two typical GPS stations during period A. Black and gray lines denote the original and filtered time series, respectively.

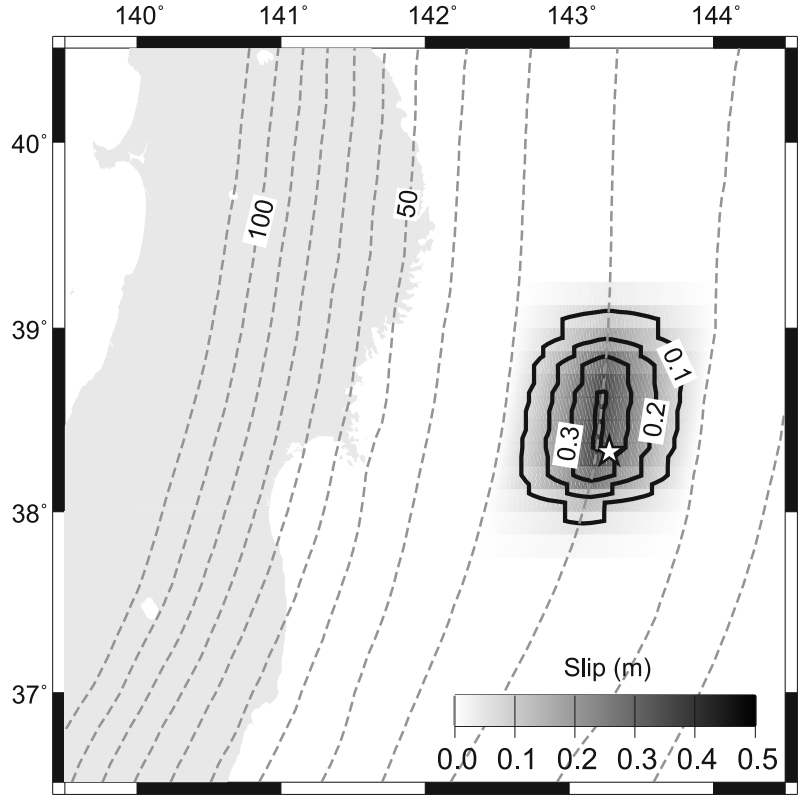

Fig. 6. The slip distribution for the foreshock. The star represents the epicenter of the foreshock.

9, and inverted for the slip at the plate boundary using the method described in the previous section. Figures 6 and 7 show the slip distribution for the foreshock and the fits to the observed offsets. The maximum slip of $0.41 \mathrm{~m}$ is found at around $\left(143.2^{\circ} \mathrm{E}, 38.4^{\circ} \mathrm{N}\right)$. The moment magnitude is estimated to be $M_{\mathrm{w}} 7.28$.

In the case of afterslip following the foreshock, since the coseismic and postseismic deformation can be expressed by using the same mode, it may be concluded that the afterslip occurred at approximately the same position as the foreshock. The detailed characteristics of the afterslip following the foreshock will be discussed in the next section.

\subsection{Mainshock and the subsequent after-} shocks/afterslips

I analyzed the position time series of 364 GEONET stations located in the area $138-143^{\circ} \mathrm{E}$ by $35-41^{\circ} \mathrm{N}$. The $\mathrm{CME}$ time series was corrected by subtracting the CME time series obtained by stacking 44 position time series of the GEONET stations that are equipped with 02-type pillars and are in the area $136-138^{\circ} \mathrm{E}$ by $34-40^{\circ} \mathrm{N}$. Note that the coseismic jump and subsequent postseismic deformations in the CME time series were removed by subtracting the coseismic offsets and postseismic exponential decay (Shen et al., 1994) in the CME time series that are estimated using the least-squares method.

To derive the coseismic deformation associated with the mainshock, I directly used the position time series of the GEONET stations without applying EOF analysis, since the associated deformations are quite large and the raw position time series are sufficient for deriving meaningful deformations.

To derive the deformation field associated with the aftershocks/afterslip, an EOF analysis was conducted for the GPS kinematic time series from 05:53 to 10:30 on March 11 (hereafter referred to as period B). The whole area was divided into two subregions, since the two aftershocks, Sanriku-oki and Ibaraki-oki, occurred within such a short time and are not discernible in the principal components if the whole GPS kinematic time series are analyzed simultaneously. The two subregions were selected as follows: (1) the northern region that consists of 97 GPS stations in the area $138-143^{\circ} \mathrm{E}$ by $38.5-41^{\circ} \mathrm{N}$, and (2) the southern 

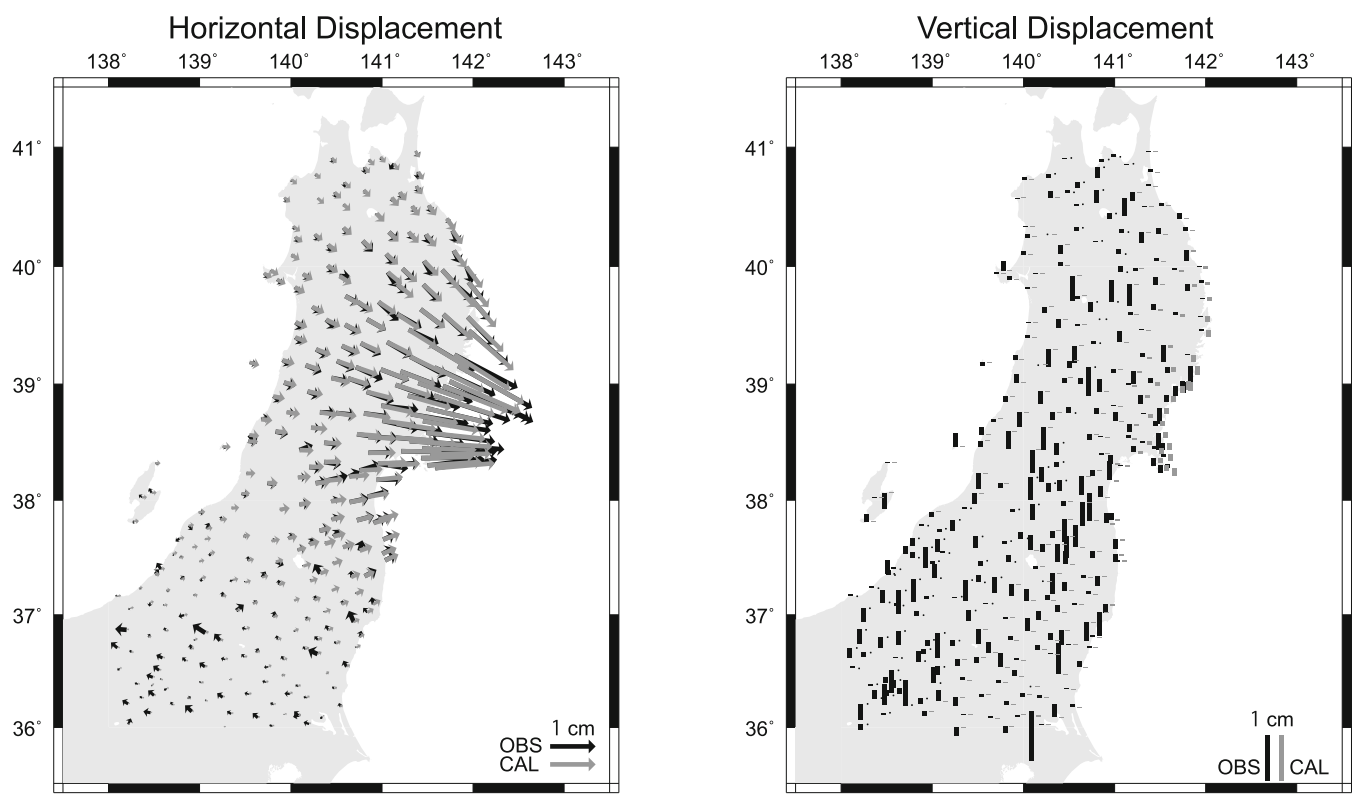

Fig. 7. The fits to the observed offsets for the foreshock; (left) horizontal, (right) vertical. Black arrows denote the observed offsets, and gray arrows represent those expected for the estimated slip distribution.
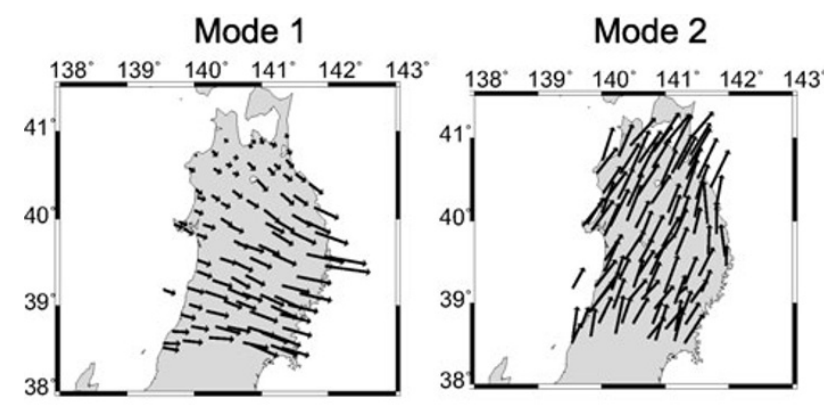

Mode 6
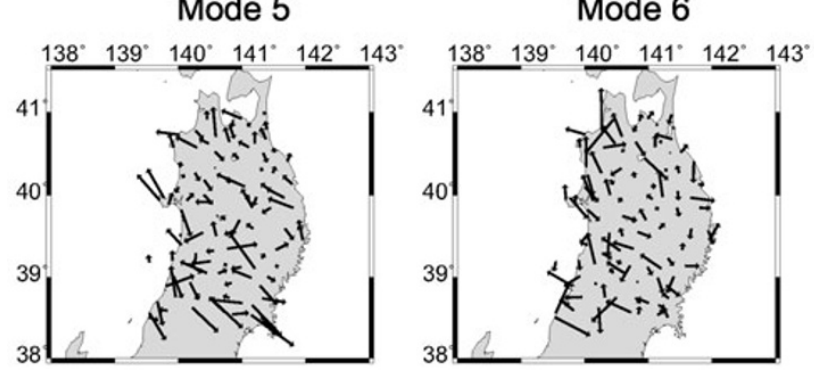
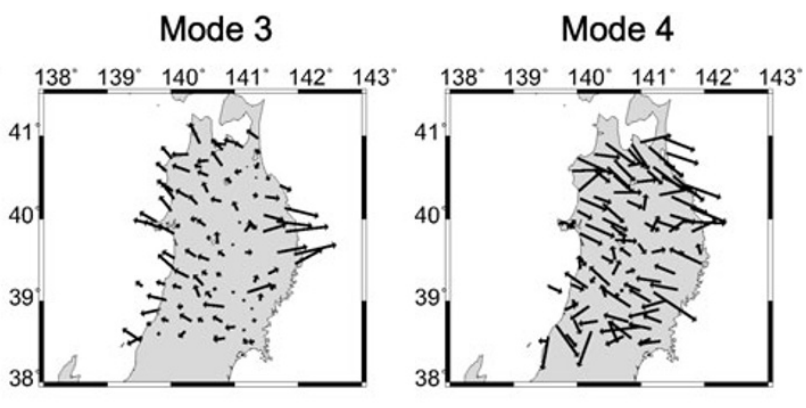

Mode 7

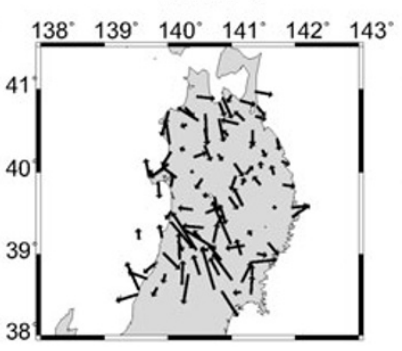

Fig. 8. The distribution of the eigenvectors for the first 8 modes for the northern region during period B.

region that consists of 239 GPS stations in the area 138$143^{\circ} \mathrm{E}$ by $35-38.5^{\circ} \mathrm{N}$. Note that the number of GPS stations used in the EOF analysis is less than the total number of GPS stations used to infer the deformations associated with the mainshock, since some tens of GPS stations went out of order soon after the mainshock because of power failure and/or tsunami attack.

The results from the EOF analysis for the northern region during period B are shown in Figs. 8-10. The eigenvectors of mode 1, as shown in Fig. 8, represent the eastward deformations that gradually decrease inland. This type of deformation is typical for thrust slip occurring on an offshore fault. The principal components of mode 1 , as shown in
Fig. 9, show an exponential behavior that is typical for afterslip and has jumps at the time of the aftershocks. Therefore, I conclude that mode 1 represents coseismic/postseismic deformations. The eigenvectors of mode 2 represent the northward shift of the majority of the stations in the network. The principal components of mode 2, as shown in Fig. 9, do not contain any patterns of postseismic relaxation, nor jumps at the occurrence of the aftershocks. Therefore, mode 2 is discarded as noise. The eigenvectors of mode 3 reveal a bipolar pattern for the western and eastern coast. The principal components of mode 3 contain a jump at the occurrence of the Sanriku-oki aftershocks and subsequent gradual changes. Therefore, I conclude that mode 3 rep- 

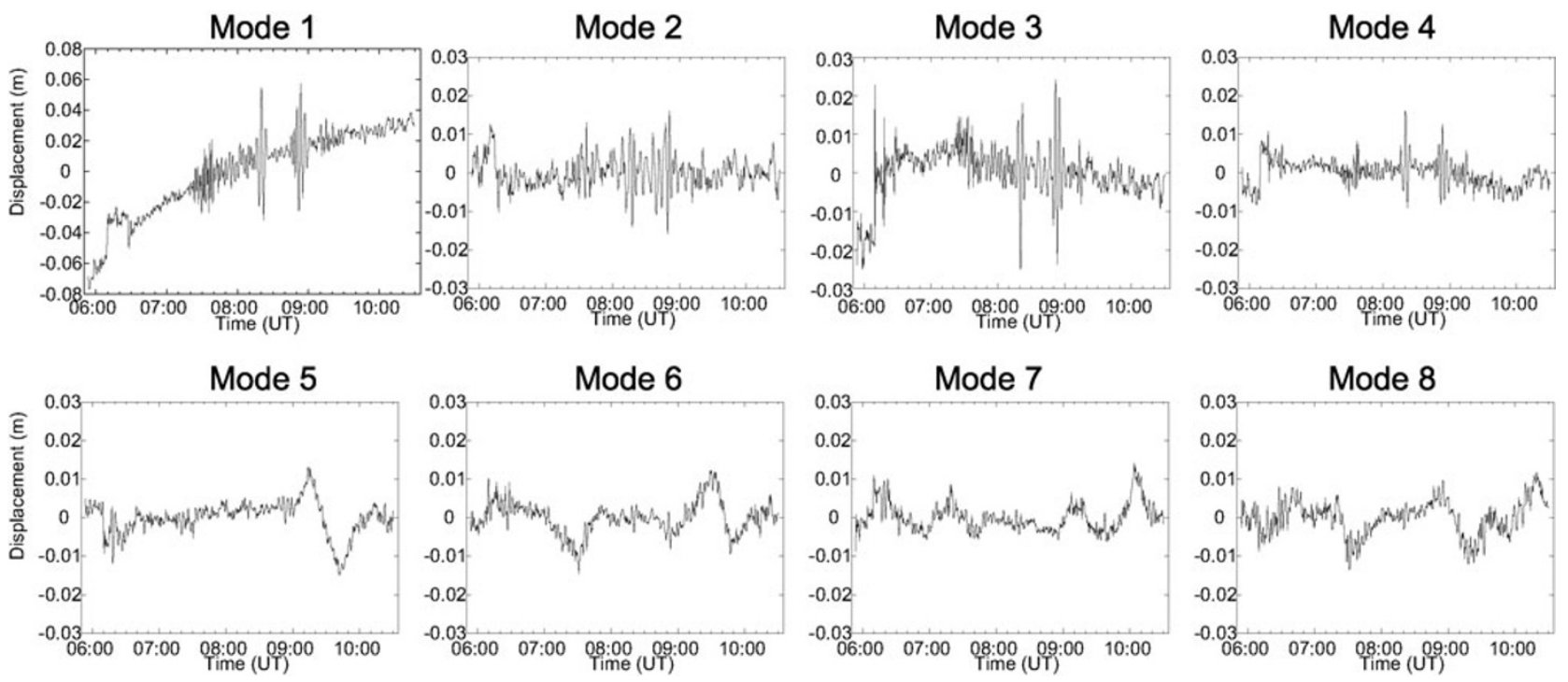

Fig. 9. The principal components for the first 8 modes for the northern region during period B.

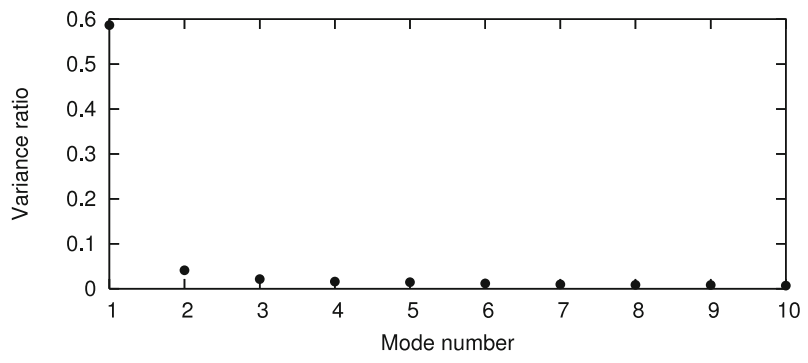

Fig. 10. The ratio of the variance of each mode to the total variance for the northern region during period $\mathrm{B}$.

resents coseismic/postseismic deformations. As for mode 4 , and other higher modes, the eigenvectors, as shown in Fig. 8, do not show any patterns that can be related to the coseismic/postseismic deformations, and their contributions to the total variances are small as shown in Fig. $10(1.6 \%$ at most). However, the principal components for modes 4 and 5 have small jumps at the occurrence of the Sanrikuoki aftershock. Therefore, I conclude that some of the coseismic deformations associated with the Sanriku-oki aftershock leaked into modes 4 and 5 and modes 4 and 5 are thus considered to be signal. Hence, I construct the filtered position time series at GEONET stations using Eq. (6) with modes $1,3,4$, and 5 .

The results from the EOF analysis for the southern region during period $\mathrm{B}$ are shown in Figs. 11-13. The eigenvectors of mode 1, as shown in Fig. 11, resemble coseismic deformation caused by thrust slip on an offshore fault. The principal components of mode 1, as shown in Fig. 12, contain a large jump at the occurrence of the Ibaraki-oki aftershock, and subsequent exponential decay. Therefore, mode 1 is considered to represent coseismic/postseismic deformations. The principal components of mode 2 also contain a large jump at the occurrence of the Ibaraki-oki aftershock, and subsequent exponential decay. Therefore, mode 2 is considered to be a signal. As for mode 3, and other higher modes, the principal components, as shown in Fig. 12, do not have jumps at the occurrence of aftershocks, or patterns resembling postseismic exponential decay, except for mode 7, which contains a small jump at the occurrence of the Ibaraki-oki aftershock. The contributions of mode 3, and other higher modes, to the total variance are small, as shown in Fig. 13 ( $0.9 \%$ at most), and the contribution of mode 7 is as small as $0.4 \%$. Therefore, I consider mode 3 , and other higher modes, to be noise. Hence, I construct the filtered position time series at the GEONET stations using Eq. (6) with modes 1 and 2 .

Figure 14 shows the position time series at two typical GEONET stations from each subregion. One can see that the coseismic jump and the subsequent postseismic deformations are well reproduced in the filtered time series.

3.2.1 Mainshock The coseismic deformation associated with the mainshock is calculated by considering the difference between the median positions at 5:40-5:45 and 5:55-6:00 on March 11, and inverted for the slip at the plate boundary. Figures 15(a) and 16(a) show the slip distribution and the fits to the observed offsets for the mainshock, respectively. The maximum slip of $25.7 \mathrm{~m}$ is found at around $\left(142.5^{\circ} \mathrm{E}, 38.3^{\circ} \mathrm{N}\right)$. The moment magnitude is estimated to be $M_{\mathrm{w}} 8.91$.

3.2.2 Initial afterslip The initial afterslip is defined as that occurring between the mainshock and the Sanrikuoki aftershock. The deformation associated with the initial afterslip is calculated by considering the difference between the median positions at 5:53-5:58 and 6:03-6:08 on March 11 and inverted for the slip at the plate boundary. Figures 15(b) and 16(b) show the slip distribution and the fits to the observed offsets for the initial afterslip, respectively. Comparing with Fig. 15(a), one can see the slip has propagated into the adjacent region to the north, and downdip of the mainshock slip area. The maximum slip of $4.7 \mathrm{~cm}$ is found at around $\left(142.7^{\circ} \mathrm{E}, 39.7^{\circ} \mathrm{N}\right)$. The moment magnitude of the afterslip is estimated to be $M_{\mathrm{w}} 7.08$ over this 10-minute period.

3.2.3 Sanriku-oki aftershock The coseismic deformations of the Sanriku-oki aftershock are calculated by 

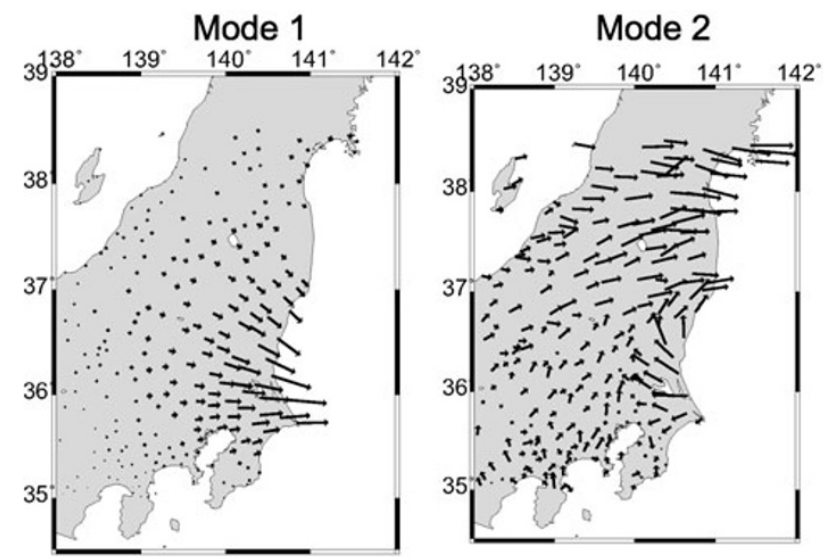

Mode 5

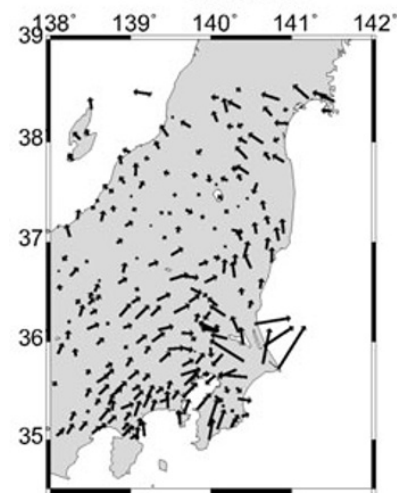

Mode 6

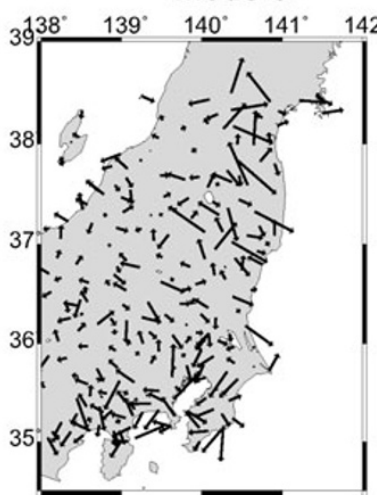

Mode 3

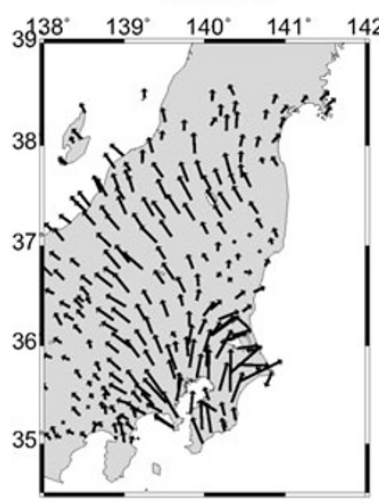

Mode 7

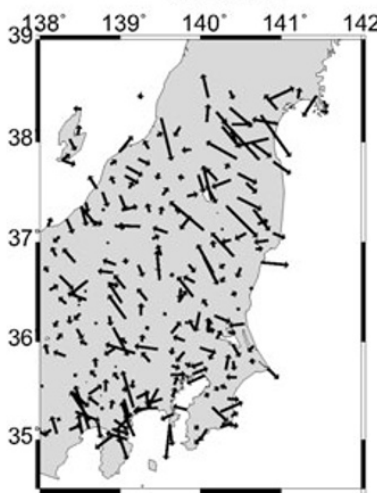

Mode 4

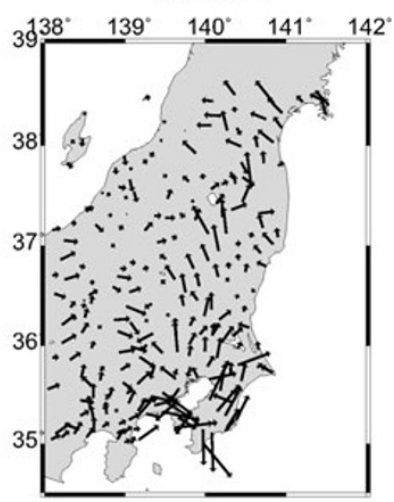

Mode 8

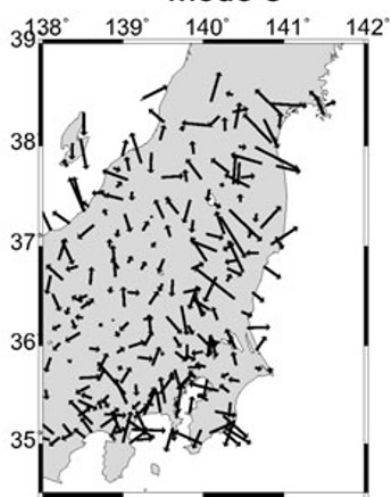

Fig. 11. The distribution of the eigenvectors for the first 8 modes for the southern region during period B.

Mode 1

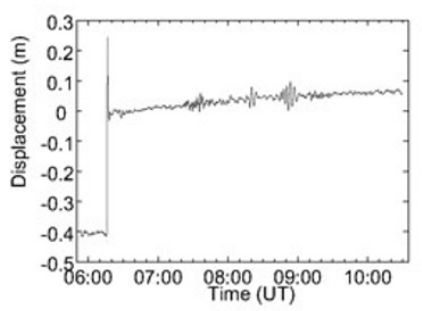

Mode 5

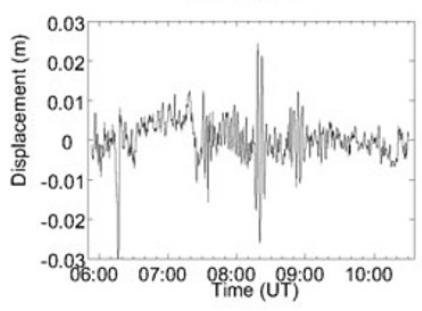

Mode 2

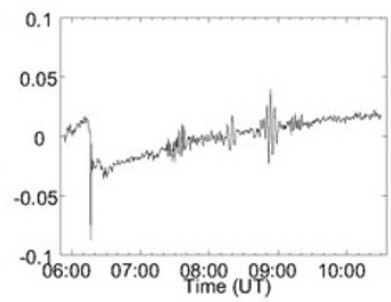

Mode 6

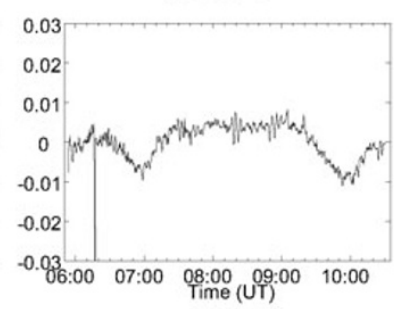

Mode 3

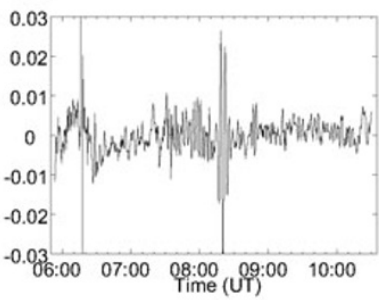

Mode 7

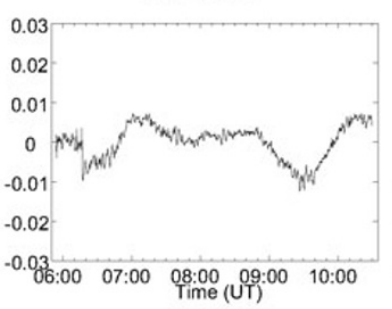

Mode 4

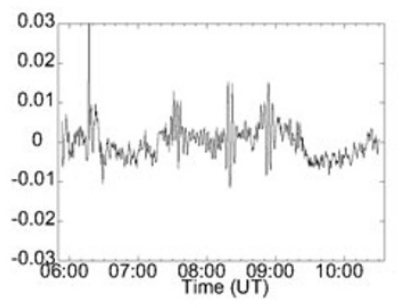

Mode 8

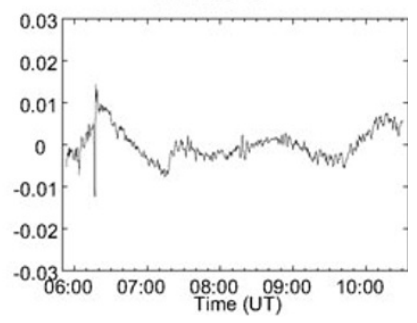

Fig. 12. The principal components for the first 8 modes for the southern region during period B.

considering the difference between the median positions at 6:02-6:07 and 6:09-6:14 on March 11, and inverted for the slip at the plate boundary. Figures 15(c) and 16(c) show the slip distribution and the fits to the observed offsets for the Sanriku-oki aftershock, respectively. One can see that the rupture area overlaps the region north of the mainshock where the initial afterslip was observed. The maximum slip of $0.44 \mathrm{~m}$ is found at around $\left(142.7^{\circ} \mathrm{E}, 39.9^{\circ} \mathrm{N}\right)$. The mo- ment magnitude is estimated to be $M_{\mathrm{w}} 7.36$.

3.2.4 Ibaraki-oki aftershock The coseismic deformation associated with the Ibaraki-oki aftershock is calculated by considering the difference between the median positions at 6:10-6:15 and 6:20-6:25 on March 11, and inverted for the slip at the plate boundary. Figures 15(d) and 16(d) show the slip distribution and the fits to the observed offsets for the Ibaraki-oki afterslip, respectively. One can 


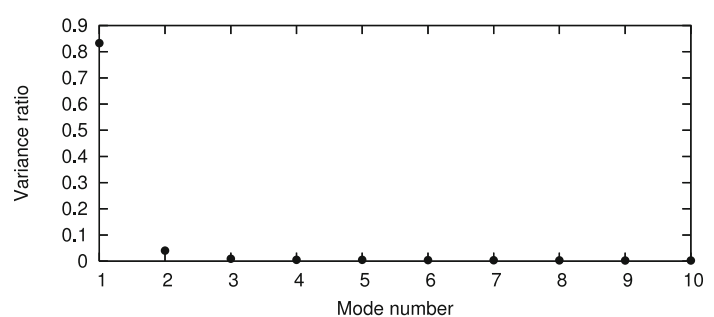

Fig. 13. The ratio of the variance of each mode to the total variance for the southern region during period $\mathrm{B}$.

see that the aftershock occurred at the southern tip of the initial afterslip area. The maximum slip of $3.6 \mathrm{~m}$ is found at around $\left(142.7^{\circ} \mathrm{E}, 36.5^{\circ} \mathrm{N}\right)$. The moment magnitude is estimated to be $M_{\mathrm{w}} 7.78$.

3.2.5 Outer-rise aftershock The coseismic deformation associated with the outer-rise aftershock is calculated by considering the difference between the median positions at 6:19-6:24 and 6:27-6:32 on March 11. In this case, I assumed a simple rectangular fault in an elastic half-space and solved for fault parameters (location, depth, length, width, strike, dip, rake, and slip) by a combination of grid search and simulated annealing, since the epicenter is far from the coastline and the GPS stations on land do not allow a detailed slip estimation. Figures 17 and 18 show the rectangular fault model for the outer-rise aftershock and the fits to the observed offsets. The slip on the fault is estimated to be $1.79 \mathrm{~m}$, and the moment magnitude is estimated to be $M_{\mathrm{w}}$ 7.40. The estimated fault parameters for this earthquake are listed in Table 1.

3.2.6 Early afterslip Here, the early afterslip is tentatively defined as that occurring during approximately the first $4 \mathrm{~h}$ after the Ibaraki-oki aftershock. The deformation associated with the early afterslip is calculated by considering the difference between the median positions at 6:306:35 and 10:25-10:30 on March 11, and inverted for the slip at the plate boundary. Figures 19 and 20 show the slip distribution for the early afterslip and the fits to the observed offsets. By comparing Fig. 19 with Fig. 15, one can see the slip propagated into the regions updip and downdip of the initial slip area, and also propagated both north and south of the rupture area of the Ibaraki-oki aftershock. The maximum slip of $20.5 \mathrm{~cm}$ is found at around $\left(143.3^{\circ} \mathrm{E}, 39.9^{\circ} \mathrm{N}\right)$. The moment magnitude is estimated to be $M_{\mathrm{w}} 7.77$ over this 4-hour period.

\section{Discussion}

\subsection{Characteristics of the afterslip following the fore-} shock

I mentioned in Section 3.1 that the coseismic, and subsequent postseismic, deformations of the foreshock can be described by a single mode (mode 1 ). This fact suggests that a single mechanism is involved for both deformations and the extent of the source must be similar (Savage and Svarc, 2009). Therefore, I conclude that the postseismic deformations are caused by the afterslip and the slip area for the afterslip is similar to that of the foreshock.

Chang and Chao (2011) reported an apparent reversal in the eastward EOF time series of mode 1 after the foreshock, while I did not see any signs of such a reversal, as is apparent in Fig. 3. The difference between the two studies may be due to the data used (30-s sampling in this study, as opposed to 30-min sampling in Chang and Chao (2011)), or the EOF method used (simultaneous analysis of the east and north components in this study, as opposed to the separate analysis of each component in Chang and Chao (2011)).

The principal component of mode 1, as shown in Fig. 3, can be expressed by a combination of the coseismic jump corresponding to the occurrence of the foreshock, and the subsequent exponential decay corresponding to the afterslip. Hence, I fitted the principal component with a combination of the coseismic jump and exponential decay function of the following form (Shen et al., 1994) by using the least-squares method:

$$
f(t)=a+\left[b+c\left(1-e^{-\left(t-\tau_{0}\right) / \tau}\right)\right] H\left(t-\tau_{0}\right),
$$

where $H(t)$ represents the Heaviside function, and $\tau_{0}$ denotes the time of occurrence of the foreshock. I obtained the scaling parameter $\frac{c}{b}=0.58$ and decay time $\tau=0.63$ days.

When coseismic deformation, and subsequent postseismic deformation, are described by a single mode, and the slip area of the coseismic slip and afterslip can be considered as similar, the ratio of the seismic moments of the earthquake and subsequent afterslip is the same as that of the coseismic jump and afterslip amplitude in the corresponding principal component. That is, in our case, the following relationship holds:

$$
M_{0}^{\text {afterslip }}=M_{0}^{\text {foreshock }} \frac{c}{b}\left(1-e^{-\tau_{e} / \tau}\right),
$$

where $M_{0}^{\text {foreshock }}$, and $M_{0}^{\text {afterslip }}$ represent the seismic moments of the foreshock and afterslip, respectively, and $\tau_{e}$ denotes the elapsed time from the occurrence of the foreshock. Now I calculate the moment magnitude of the afterslip of the foreshock by the occurrence of the mainshock. By substituting $M_{0}^{\text {foreshock }}=1.04 \times 10^{20} \mathrm{~N} \mathrm{~m}$ (equivalent to the moment magnitude of the foreshock $\left.M_{\mathrm{w}} 7.28\right), \frac{c}{b}=0.58$, and $\tau_{e}=2.14$ days in the above equation, the seismic moment is obtained for the afterslip as $M_{0}^{\text {afterslip }}=5.86 \times 10^{19} \mathrm{~N} \mathrm{~m}$, or equivalent moment magnitude of $M_{\mathrm{w}}^{\text {afterslip }} 7.11$, which is consistent with $M_{\mathrm{w}} \sim 7.0$, as obtained by Miyazaki et al. (2011).

Equation (7) fits the principal component of mode 1 very well and there is no sign of a gradual increase in the principal component just before the mainshock. Together with the fact that the postseismic deformation can be expressed well using mode 1 only, it can be concluded that no acceleration of quasistatic slip has been detected that could have hinted at the occurrence of a future mainshock between the occurrence of the foreshock and the mainshock.

The characteristics of the afterslip have been independently investigated by considering small repeating earthquakes. Kato et al. (2012) evaluated the spatio-temporal development of quasistatic slip at the plate boundary around the focal area of the foreshock. One of their results was that the quasistatic slip occurred in the focal area of the foreshock after the occurrence of the foreshock, and the temporal development of quasistatic slip resembles that of the 

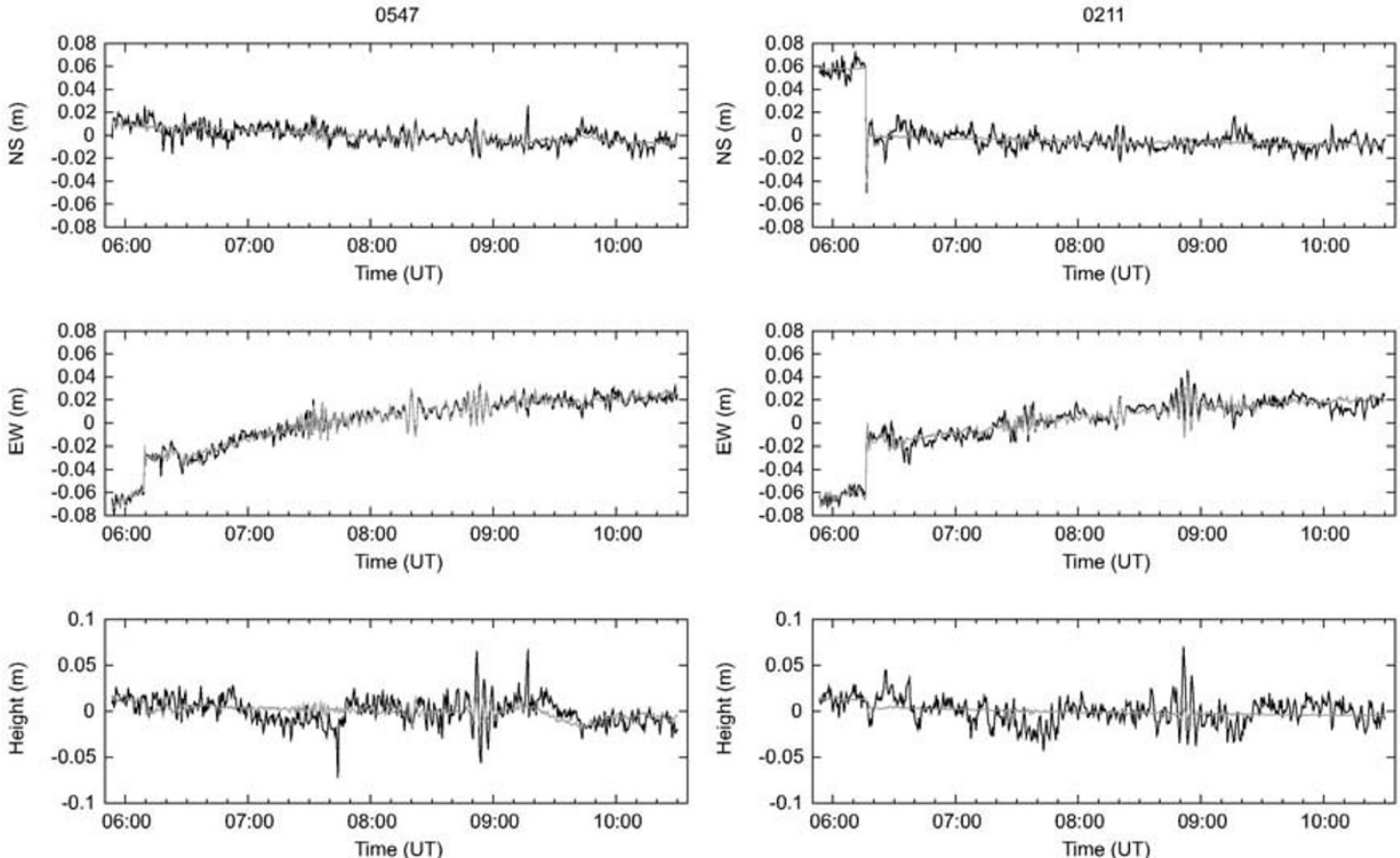

Fig. 14. The position time series at two typical GPS stations during period B. Station 0547 belongs to the northern region, and 0211 belongs to the southern region. The legends are the same as for Fig. 5.
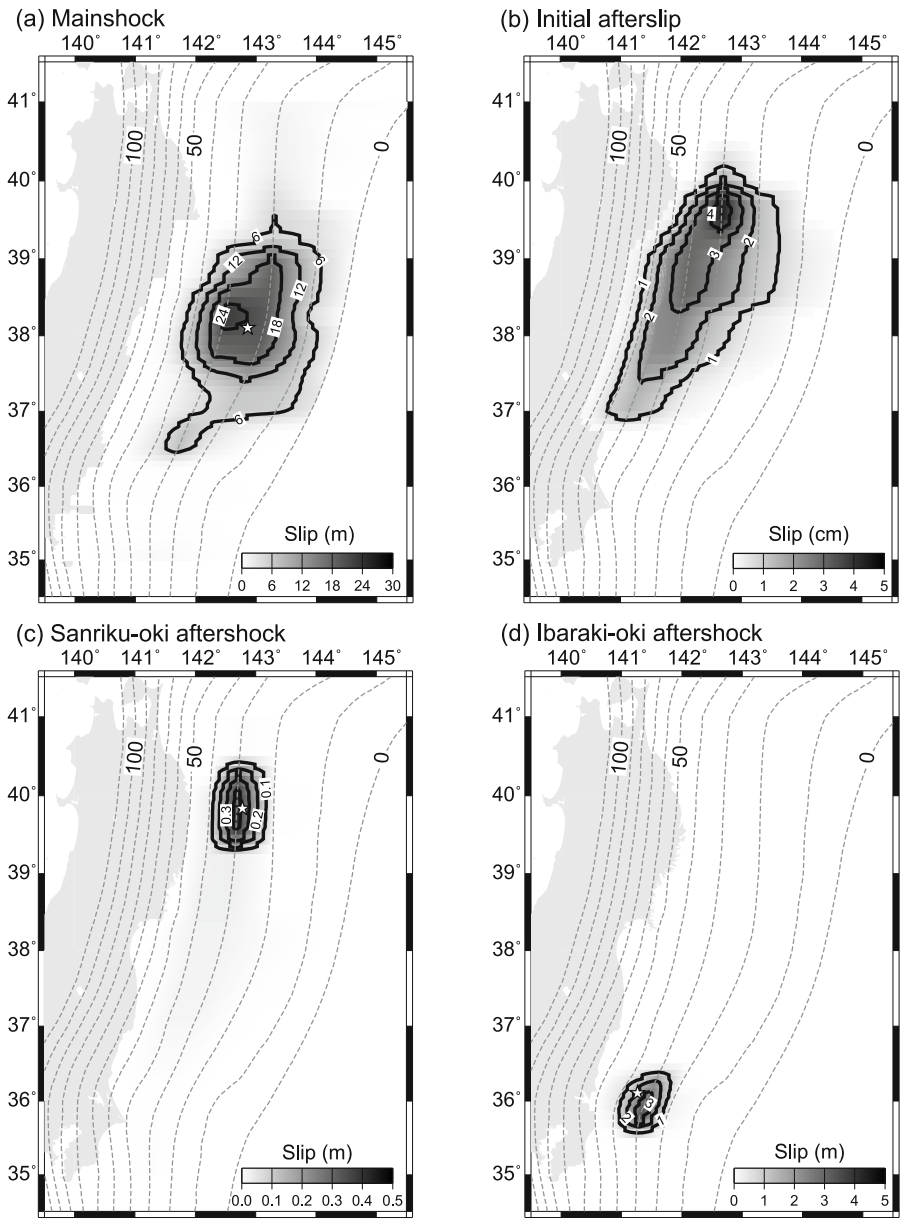

Fig. 15. The slip distributions for (a) mainshock, (b) initial afterslip, (c) Sanriku-oki aftershock, and (d) Ibaraki-oki aftershock. The legends are the same as for Fig. 6. 
(a) Mainshock

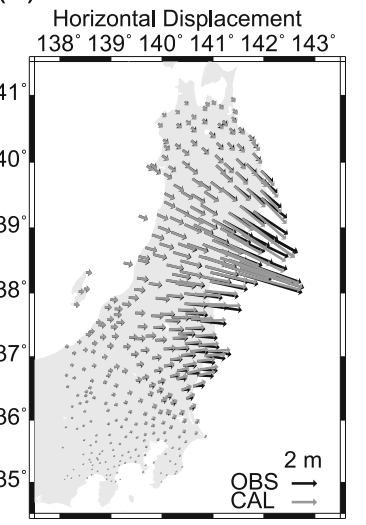

(c) Sanriku-oki aftershock
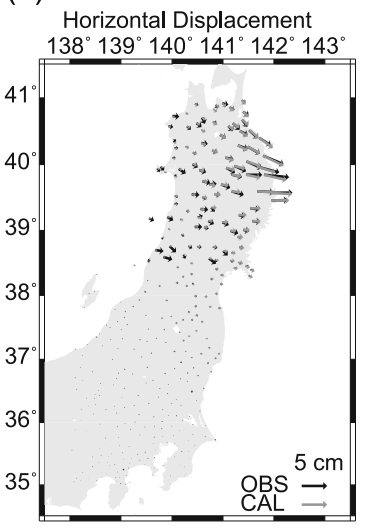
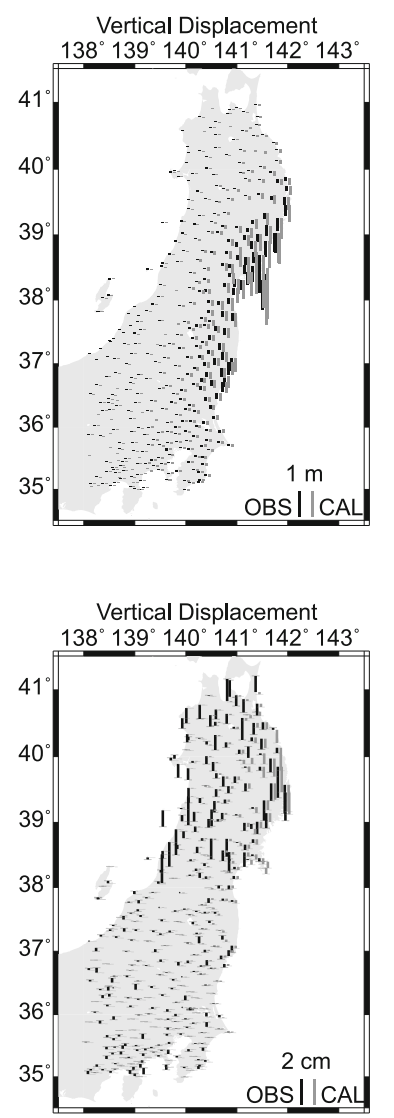

(b) Initial afterslip

Horizontal Displacement $138^{\circ} 139^{\circ} 140^{\circ} 141^{\circ} 142^{\circ} 143^{\circ}$
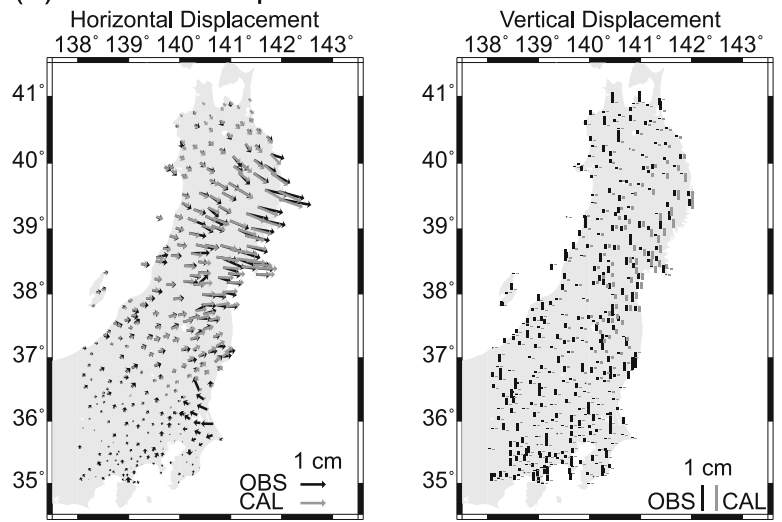

(d) Ibaraki-oki aftershock Horizontal Displacement $138^{\circ} 139^{\circ} 140^{\circ} 141^{\circ} 142^{\circ} 143^{\circ}$

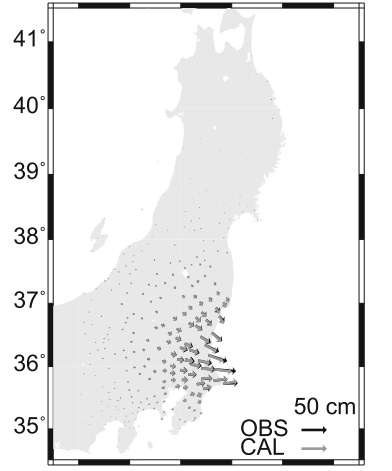

Vertical Displacement

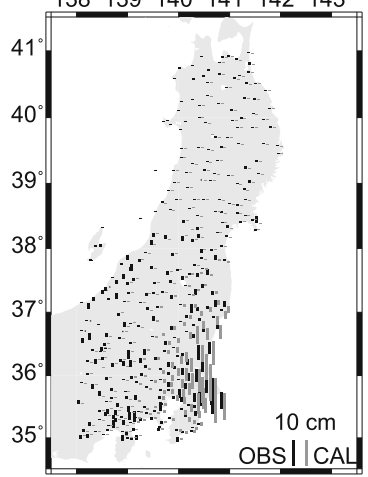
$138^{\circ} 139^{\circ} 140^{\circ} 141^{\circ} 142^{\circ} 143^{\circ}$

Fig. 16. The fits to the observed offsets for (a) mainshock, (b) initial afterslip, (c) Sanriku-oki aftershock, and (d) Ibaraki-oki aftershock. The legends are the same as for Fig. 7.

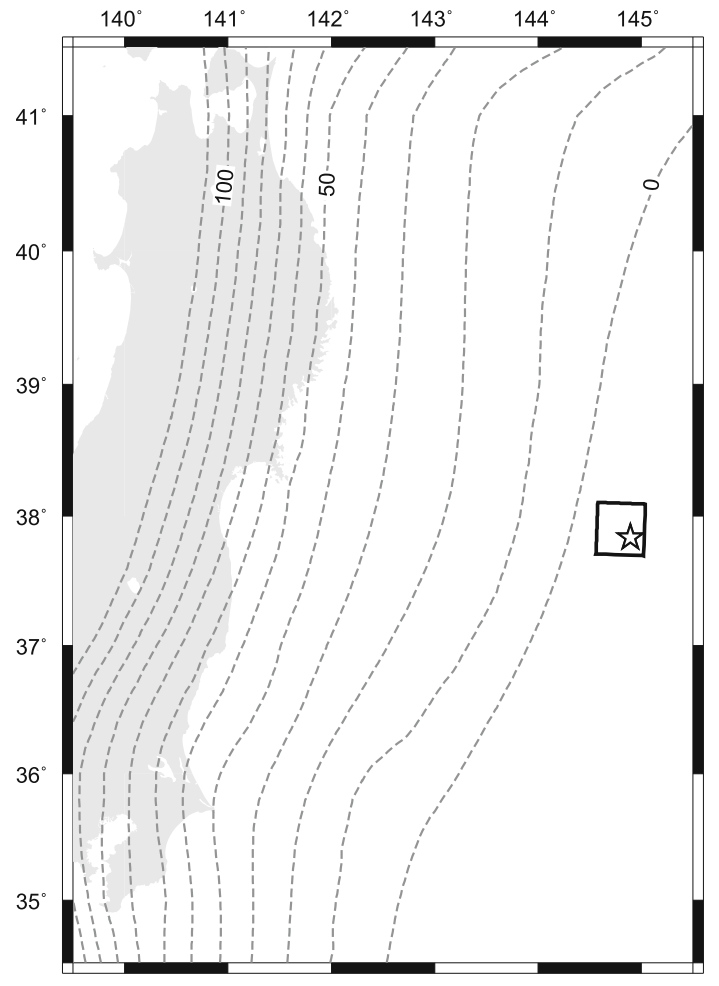

Fig. 17. The rectangular fault model for the outer-rise aftershock. afterslip in the northern and middle part of the focal area of the foreshock. These results are consistent with our findings that the slip area for the afterslip is similar to that of the foreshock, and temporal development of the afterslip can be well described by the exponential-decay function. On the other hand, they found that in the southern part of the focal area of the foreshock, quasistatic slip propagated in the south-south-east direction toward the epicenter of the mainshock, and the accumulated quasistatic slip linearly increased with time. I failed to detect modes in the EOF that represent such features. Since this area is far from the coastline $(>100 \mathrm{~km})$, it may be possible that land-based GPS stations do not offer enough spatial resolution in the slip inversion to permit us to isolate such slip. The use of oceanbottom pressure gauges (Hino et al., 2011) might be helpful in detecting such slips.

Finally, I investigated whether the magnitude of the afterslip is unusual for its duration. Ide et al. (2007) proposed a scaling relation for slow earthquakes that holds between seismic moment and characteristic duration. I compared the case of this afterslip with their scaling relation (Fig. 21), and found that the duration and magnitude of this afterslip is an exception to their scaling law, and the magnitude is larger for the duration than that expected for slow slip. However, two earthquakes that previously occurred in the adjacent region (the 1989 and 1992 Sanriku-oki earthquakes; Kawasaki et al., 2001) are also exceptions to their scaling law, and occupy a similar region. The fact that these three 

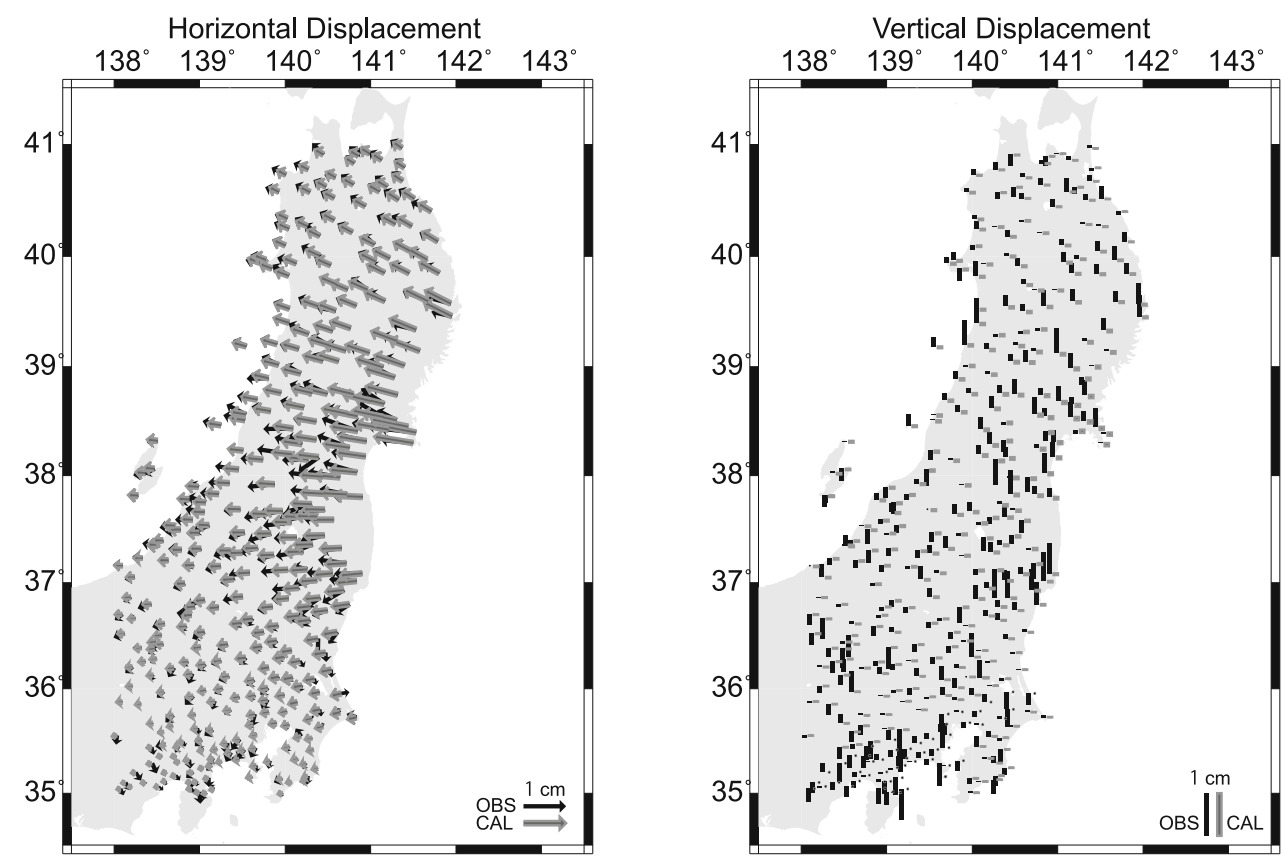

Fig. 18. The fits to the observed offsets for the outer-rise aftershock. The legends are the same as for Fig. 7.

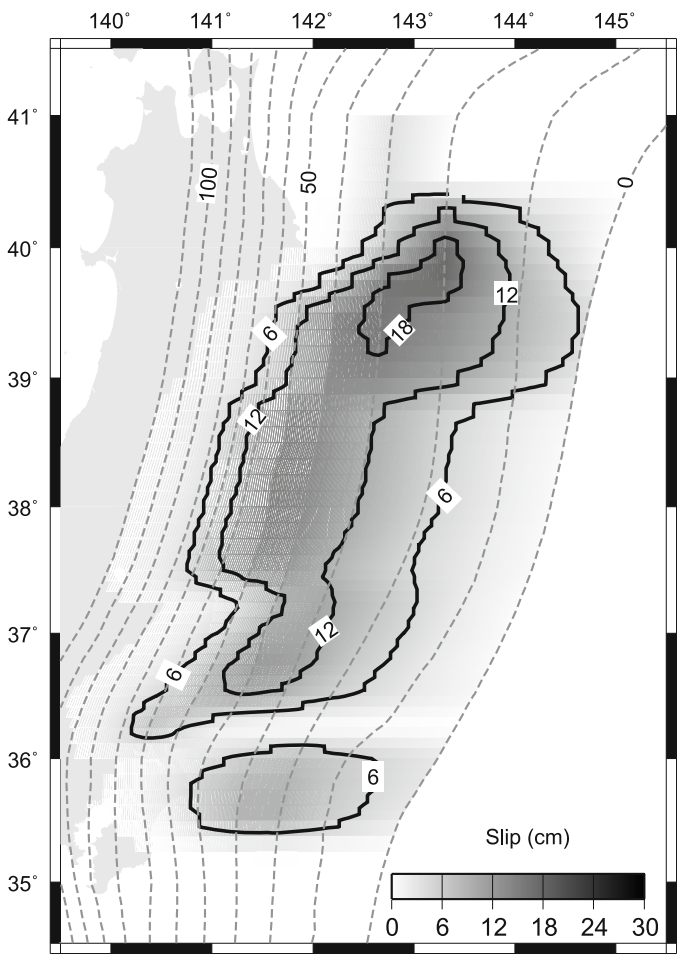

Fig. 19. The slip distribution for the early afterslip.

earthquakes caused a larger afterslip for the given duration may reflect some regional conditions at the plate boundary around this area.

\subsection{Spatial distribution of the aftershock and afterslip following the mainshock}

The slip patterns of the mainshock, the subsequent afterslip and the aftershocks, as revealed in Figs. 15 and 19, clearly indicate that each phase of slip occurs in a region adjacent to the previous phase of slip in a complementary manner. Comparing Fig. 15(b) with Fig. 15(a), one can see that the initial afterslip occurred mainly in the downdip region and the northern adjacent region to the mainshock rupture area. The northern adjacent region to the mainshock rupture area was subsequently ruptured by the subsequent Sanriku-oki aftershock, as shown in Fig. 15(c). Subsequently, the Ibaraki-oki aftershock occurred at the southern tip of the initial afterslip area (Fig. 15(d)). Thereafter, the early afterslip occurred in the northern and southern adjacent regions of the rupture area of the Ibaraki-oki earthquake as well as in the further downdip and updip regions of the initial afterslip area (Fig. 19). The pattern of the early afterslip area is basically similar to that of the subsequent long-term afterslip area (Ozawa et al., 2011).

This type of complementary spatial pattern of coseismic rupture and afterslip or aftershock is often observed for large earthquakes (Yagi et al., 2003; Miyazaki et al., 2004). It may be interpreted as a result of previous slip transferring shear stress to the adjacent regions, which eventually triggered afterslip or aftershocks (Miyazaki et al., 2004).

\subsection{Thermal expansion of GPS pillars}

In the EOF analysis of the GPS kinematic time series during period A (Fig. 2), modes 2 and 3 represent coherent northward/southward and eastward/westward shift of the majority of the GPS stations in the network. I plotted the time series that are represented by modes 2 and 3 at a typical GPS station and the corresponding displacements in the map view on typical days in Fig. 22. The movements are mainly restricted to daytime and repeat themselves every day. In the north/south direction, the GPS stations first move northward in the morning, then southward and return to the normal position in the evening. In the east/west direction, the GPS stations first move westward in the morning, and then start to move eastward, and finally westward again to return to the normal position in the evening. These systematic movements of the GPS stations are consistent with 
Table 1. The estimated fault parameters for the outer-rise aftershock. Note that the locations represent a northern corner of an upper edge of a rectangular fault.

\begin{tabular}{cccccccccc}
\hline $\begin{array}{c}\text { Longitude } \\
\left({ }^{\circ}\right)\end{array}$ & $\begin{array}{c}\text { Latitude } \\
\left({ }^{\circ}\right)\end{array}$ & $\begin{array}{c}\text { Depth } \\
(\mathrm{km})\end{array}$ & $\begin{array}{c}\text { Length } \\
(\mathrm{km})\end{array}$ & $\begin{array}{c}\text { Width } \\
(\mathrm{km})\end{array}$ & $\begin{array}{c}\text { Strike } \\
\left({ }^{\circ}\right)\end{array}$ & $\begin{array}{c}\text { Dip } \\
\left({ }^{\circ}\right)\end{array}$ & $\begin{array}{c}\text { Rake } \\
\left({ }^{\circ}\right)\end{array}$ & $\begin{array}{c}\text { Slip } \\
(\mathrm{m})\end{array}$ & $\begin{array}{c}M_{\mathrm{w}} \\
-98.0\end{array}$ \\
\hline 145.030 & 38.090 & 22.0 & 46.4 & 48.1 & 185 & 41.5 & 1.79 & 7.40 \\
\hline
\end{tabular}
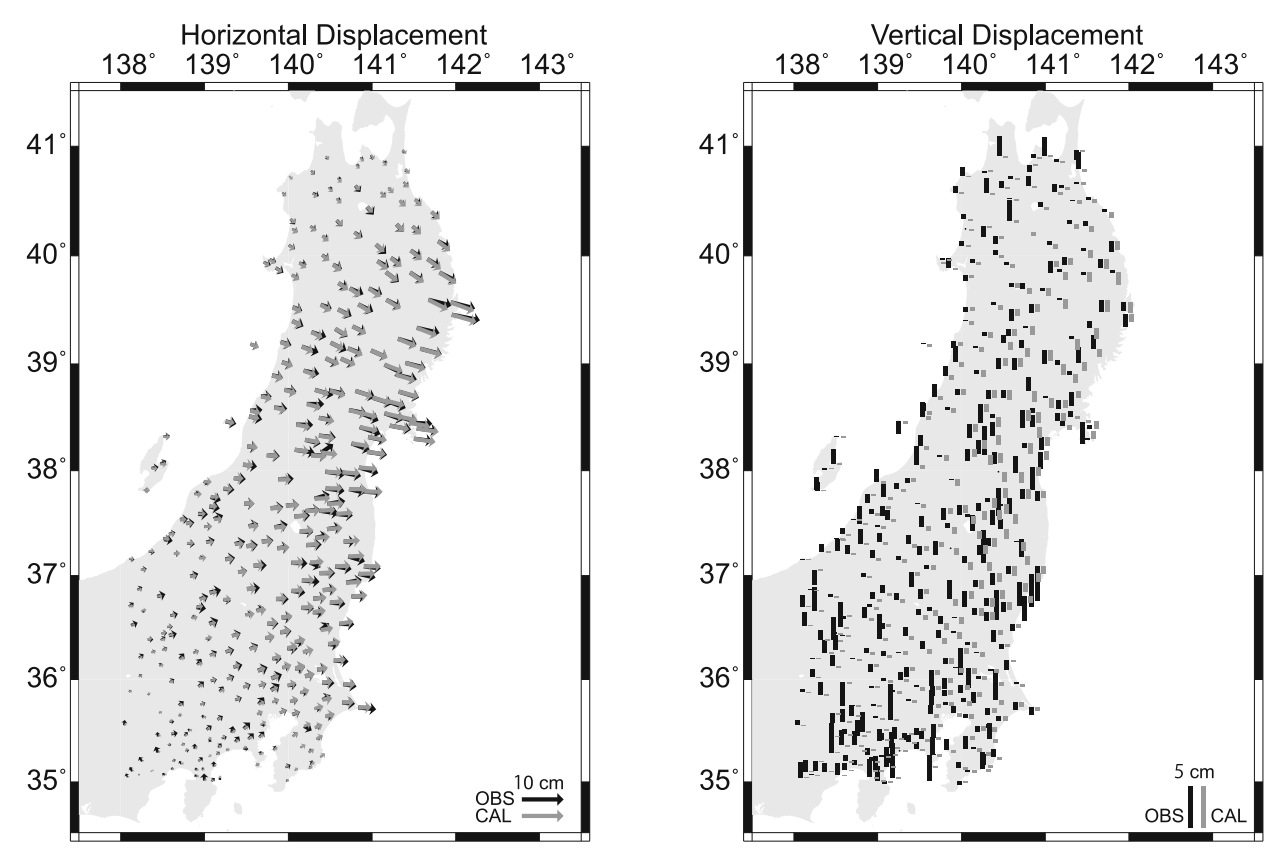

Fig. 20. The fits to the observed offsets for the early afterslip. The legends are the same as for Fig. 7.

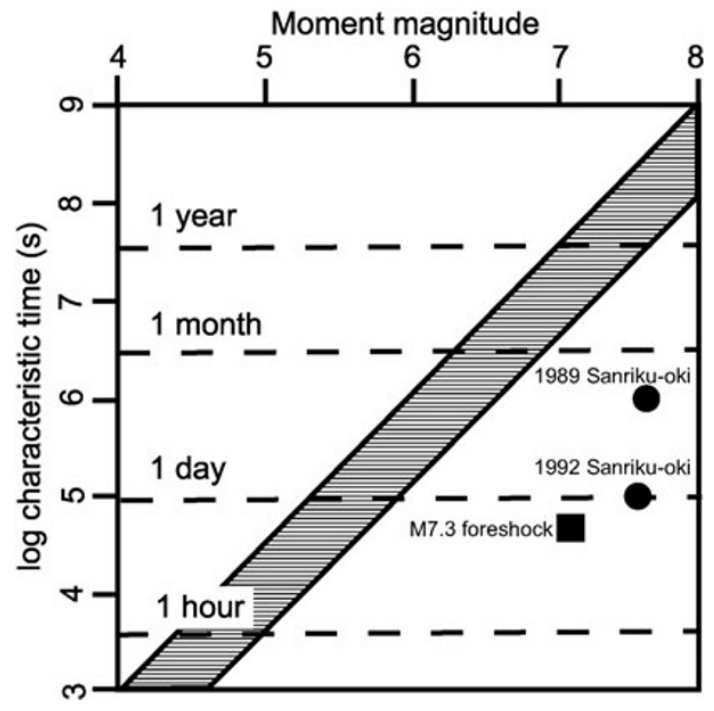

Fig. 21. Relation between characteristic time and moment magnitude of the afterslip following the foreshock of March 9. The hatched area represents the scaling law for various slow earthquakes proposed by Ide et al. (2007). Solid circles represent the cases for the 1989/1992 Sanriku-oki earthquakes (Kawasaki et al., 2001). The solid rectangle denotes the case of the afterslip following the $M_{\mathrm{W}} 7.3$ foreshock as revealed in this study.

those caused by the thermal expansion of the GPS pillars (Hatanaka et al., 2005). Therefore, I conclude that modes 2 and 3 represent the thermal expansion of the GPS pillars. One can see that on March 7, the deformations are small compared to those on other days. This is consistent with it being cloudy in most of the studied area on March 7 .

The eigenvectors of modes 2 and 3, as shown in Fig. 2, have some spatial variations. For the GPS stations with 93-, 94-, and 95-type pillars, the average northward eigenvector element is 0.59 with a standard deviation of 0.14 , and the average eastward eigenvalue element is 0.33 with a standard deviation of 0.17 . The nonuniform distribution of the eigenvector element may reflect variations of the local environment surrounding the GPS stations, such as the shading from sunlight by buildings or the nature of the ground (e.g., grass or concrete). On the other hand, the eigenvector elements of the GPS stations with 02-type pillars are relatively small: the average northward eigenvector element is 0.20 with a standard deviation of 0.22 , and the average eastward eigenvector element is 0.06 with a standard deviation of 0.19. The small eigenvector elements for the GPS stations with 02-type pillars reflect the fact that the 02-type pillars are equipped with coaxial dual stainless steel tubes and their thermal expansions are small.

\section{Summary}

I have estimated the slip distributions for the 2011 Tohoku-oki earthquake sequence using the GPS kinematic time series that are filtered by EOF analysis. I found that the $M_{\mathrm{w}} 7.3$ foreshock that occurred on March 9 and the subsequent afterslip, ruptured a similar region. No acceleration of quasistatic slip was observed that might hint at the occurrence of a future mainshock. The time evolution of the af- 


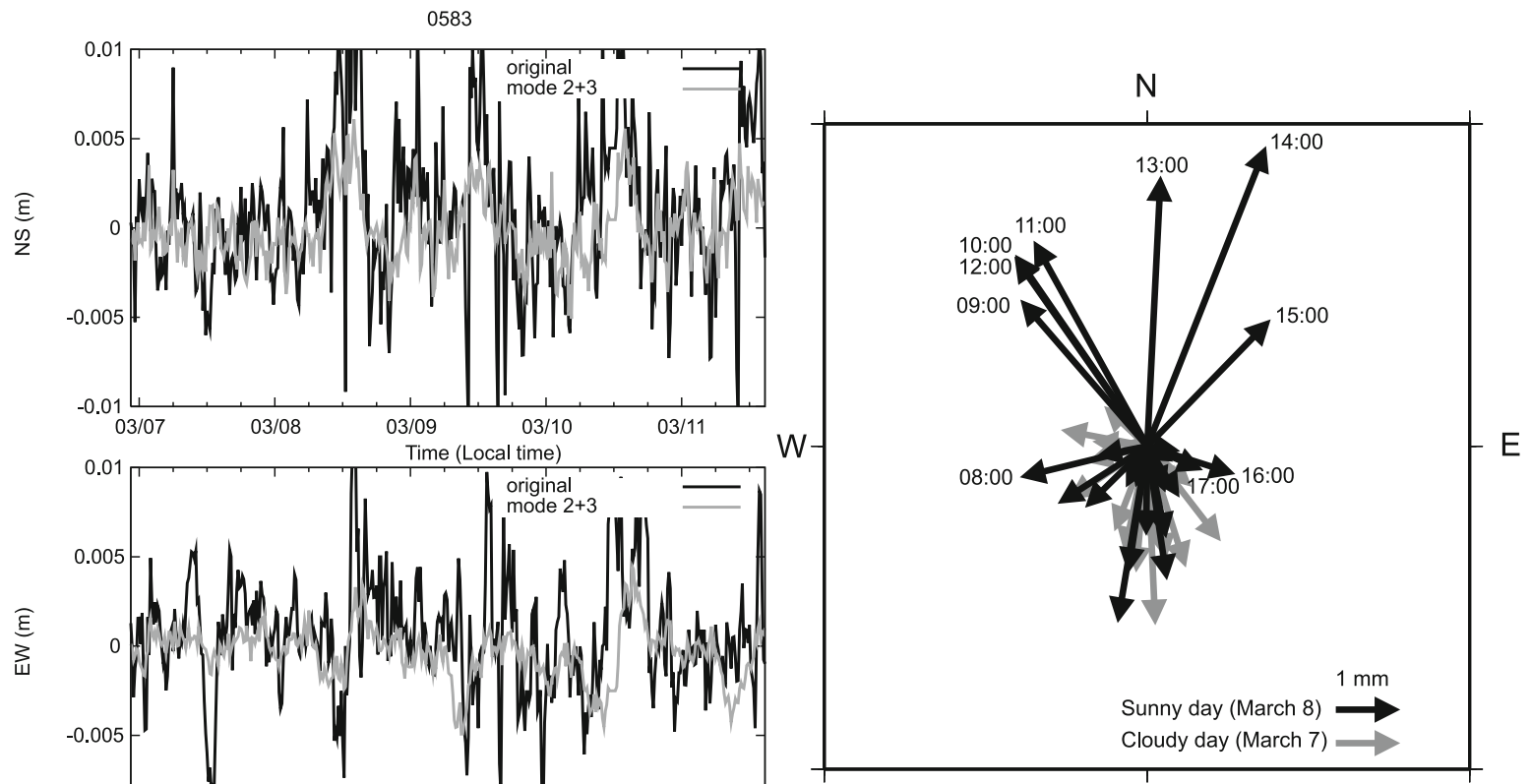

S

Fig. 22. Displacements due to thermal expansion of GPS pillars; (left) Comparison of the position time series corresponding to the sum of modes 2 and 3, which are considered to represent the thermal expansion of a pillar, with the original time series at a typical GPS station. The black line denotes the original position time series, and the gray line denotes the deformations represented by the sum of modes 2 and 3 . Note that both time series are smoothed with a 900-s moving window and are plotted w.r.t. the local time (Japan Standard Time). (right) The map view of displacements represented by the sum of modes 2 and 3. Black vectors denote displacements on a sunny day (March 8), and gray vectors denote those on a cloudy day (March 7). Numbers associated with the red vectors represent the local time at which the displacements were observed on March 8.

terslip following the foreshock can be described by a simple exponential decay, and the relationship between the magnitude and duration of the afterslip seems to be similar to that of the earthquakes that previously occurred in the adjacent region, although it does not follow the scaling law of Ide et al. (2007). The areas of slip in the mainshock and the following afterslip and aftershocks are found to be complementary with each other, which may suggest that previous slip increased stresses on adjacent regions to trigger future aftershocks or afterslip. Finally, in the EOF analysis, I identified modes corresponding to the thermal expansion of the GPS pillars, and successfully removed the noise from the original GPS kinematic time series.

In this study, I have demonstrated that EOF analysis is a powerful tool for enhancing the signal-to-noise ratio of GPS kinematic time series to extract meaningful deformations at the GPS stations. Network Information Filter (NIF) (Segall and Matthews, 1997) can also be used for that purpose, and Miyazaki and Larson (2008) applied it to GPS kinematic time series to infer detailed coseismic slip and subsequent afterslip at the plate boundary. EOF filtering, as used in this study, offers an easy and efficient alternative method to evaluate meaningful slips using GPS kinematic time series that contain large noise. In particular, the method will be suited for the analysis of complex time series containing deformations due to the mainshock and afterslip/aftershocks occurring within a short time, as seen in this study, where a choice of external parameters for the temporal filtering in the NIF can be complicated.
Acknowledgments. The author thanks Dr. Takuya Nishimura for critically reading the earlier version of the manuscript. The constructive comments by Jeff Freymueller and an anonymous reviewer significantly improved the manuscript. The earthquake catalog was provided by the Japan Meteorological Agency.

\section{References}

Aoki, Y. and C. H. Scholz, Vertical deformation of the Japanese islands, 1996-1999, J. Geophys. Res., 108, 2257, doi:10.1029/2002JB002129, 2003.

Bertiger, W., S. D. Desai, B. Haines, N. Harvey, A. W. Moore, S. Owen, and J. P. Weiss, Single receiver phase ambiguity resolution with GPS data, J. Geod., 84, 327-337, 2010.

Boehm, J., B. Werl, and H. Schuh, Troposphere mapping functions for GPS and very long baseline interferometry from European Centre for Medium-Range Weather Forecasts operational analysis data, J. Geophys. Res., 111, B02406, doi:10.1029/2005JB003629, 2006.

Chang, E. T. Y. and B. F. Chao, Co-seismic surface deformation of the 2011 off the Pacific coast of Tohoku Earthquake: Spatio-temporal EOF analysis of GPS data, Earth Planets Space, 63, 649-654, 2011.

Desai, S. D., W. Bertiger, B. Haines, N. Harvery, C. Selle, A. Sibthorpe, and J. P. Weiss, Results from the reanalysis of global GPS data in the IGS08 reference frame, paper presented at the American Geophysical Union fall meeting 2011, San Francisco, 2011.

Dong, D., P. Fang, Y. Bock, F. Webb, L. Prawirodirdjo, S. Kedar, and P. Jamason, Spatiotemporal filtering using principal component analysis and Karhunen-Loeve expansion approaches for regional GPS network analysis, J. Geophys. Res., 111, B03405, doi:10.1029/2005JB003806, 2006

Hatanaka, Y., A. Yamagiwa, T. Yutsudo, and B. Miyahara, Evaluation of precision of routine solutions of GEONET, J. Geogr. Surv. Inst., 108, 49-56, 2005 (in Japanese with English abstract).

Hino, R., D. Inazu, Y. Ito, T. Iinuma, Y. Ohta, S. Suzuki, Y. Osada, M. Kido, H. Fujimoto, M. Snihohara, and Y. Kaneda, Crustal deformation associated with the 2011 off the Pacific coast of Tohoku earthquake and its foreshock, paper presented at the Seismological Society of Japan 2011 fall meeting, Shizuoka, 2011. 
Ide, S., G. C. Beroza, D. R. Shelly, and T. Uchide, Scaling law for slow earthquakes, Nature, 447, 76-79, 2007.

Ito, T., K. Ozawa, T. Watanabe, and T. Sagiya, Slip distribution of the 2011 off the Pacific coast of Tohoku Earthquake inferred from geodetic data, Earth Planets Space, 63, 627-630, 2011.

Iwabuchi, T., Y. Shoji, S. Shimada, and H. Namamura, Tsukuba GPS dense net campaign observations: comparison of the stacking maps of the postfit phase residuals estimated from three software package, J. Meteor. Soc. Jpn., 82, 315-330, 2004

Kato, A., K. Obara, T. Igarashi, H. Tsuruoka, S. Nakagawa, and N. Hirata, Propagation of slow slip leading up to the $2011 M_{w} 9.0$ Tohoku-oki earthquake, Science, 335, 705-708, 2012.

Kawasaki, I., Y. Asai, and Y. Tamura, Space-time distribution of interplate moment release including slow earthquakes and the seismo-geodetic coupling in the Sanriku-oki region along the Japan trench, Tectonophysics, 330, 267-283, 2001.

Matsumoto, K., T. Takanezasa, and M. Ooe, Ocean tide models developed by assimilating TOPEX/POSEIDON altimeter data into hydrodynamical model: a global model and a regional model around Japan, $J$. Oceanogr., 56, 567-581, 2000.

Matsumoto, K., T. Sato, T. Takanezasa, and M. Ooe, A program for computation of oceanic tidal loading effect, J. Geod. Soc. Jpn., 47, 243-248, 2001.

McCaffrey, R., Time-dependent inversion of three-component continuous GPS for steady and transient sources in northern Cascadia, Geophys. Res. Lett., 36, L07304, doi:10.1029/2008GL036784, 2009.

Miyazaki, S. and K. Larson, Coseismic and early postseismic slip for the 2003 Tokachi-oki earthquake sequence inferred from GPS data, Geophys. Res. Lett., 35, L04302, doi:10.1029/2007GL032309, 2008.

Miyazaki, S., P. Segall, J. Fukuda, and T. Kato, Space time distribution of afterslip following the 2003 Tokachi-oki earthquake: Implications for variations in fault zone frictional properties, Geophys. Res. Lett., 31, L06623, doi:10.1029/2003GL019410, 2004.

Miyazaki, S., J. J. McGuire, and P. Segall, Seismic and aseismic fault slip before and during the 2011 off the Pacific coast of Tohoku Earthquake, Earth Planets Space, 63, 637-642, 2011.
Nakajima, J. and A. Hasegawa, Anomalous low-velocity zone and linear alignment of seismicity along it in the subducted Pacific slab beneath Kanto, Japan: Reactivation of subducted fracture zone?, Geophys. Res. Lett., 33, L16309, doi:10.1029/2006GL026773, 2006.

Nishimura, T., H. Munekane, and H. Yarai, The 2011 off the Pacific coast of Tohoku Earthquake and its aftershocks observed by GEONET, Earth Planets Space, 63, 631-636, 2011.

Okada, Y., Internal deformation due to shear and tensile faults in a halfspace, Bull. Seismol. Soc. Am., 82, 1018-1040, 1992.

Ozawa, S., T. Nishimura, H. Suito, T. Kobayashi, M. Tobita, and T. Imakiire, Coseismic and postseismic slip of the 2011 magnitude- 9 TohokuOki earthquake, Nature, 475, 373-376, 2011.

Savage, J. C. and J. L. Svarc, Postseismic relaxation following the 1992 M7.3 Landers and 19999 M7.1 Hector Mine earthquakes, southern California, J. Geophys. Res., 114, B01401, doi:10.1029/2008JB005938, 2009.

Segall, P. and M. Matthews, Time-dependent inversion of geodetic data, $J$. Geophys. Res., 102, 22391-22410, 1997.

Shen, Z.-K., D. D. Jackson, Y. Feng, M. Cline, M. Kim, P. Fang, and Y. Bock, Postseismic deformation following the Landers earthquake, California, 28 June 1992, Bull. Seismol. Soc. Am., 84, 780-791, 1994.

Wdowinski, S., Y. Bock, J. Zhang, P. Fang, and J. Genrich, Southern California permanent GPS geodetic array: spatial filtering of daily positions for estimating coseismic and postseismic displacements induced by the 1992 Landers earthquake, J. Geophys. Res., 102, 18057-18070, 1997.

Yagi, Y., M. Kikuchi, and T. Nishimura, Co-seismic slip, postseismic slip, and largest aftershock associated with the 1994 Sanriku-haruka-oki, Japan, earthquake, Geophys. Res. Lett., 30, 2177, doi:10.1029/2003GL018189, 2003.

Zumberge, J. F., M. B. Heflin, D. C. Jefferson, M. M. Watkins, and F. H. Webb, Precise point positioning for the efficient and robust analysis of GPS data from large networks, J. Geophys. Res., 102, 5005-5018, 1997.

H. Munekane (e-mail: munekane@gsi.go.jp) 